\title{
Developing the ISA's Environmental Mandate Through the Mining Code
}

\subsection{Introduction}

An excellent example of the way in which the Regulations significantly develop the legal regime for the Arvea is the section on the protection of the marine environment. ${ }^{1}$

The core question of this study is: whether, and in what manner and to what extent, is the International Seabed Authority (ISA) implementing the precautionary principle? The previous chapters provide the background analysis to this question. Chapters 1 and 2 discuss the context for this study regarding the environmental risks of seabed mining and the precautionary principle respectively. Chapter 3 introduces the ISA's institutional competencies and decisionmaking processes and Chapter 4 discusses the environmental mandate of the ISA.

This chapter begins to formulate the answer to this core research question through an analysis of the manner in which the ISA has developed the legal framework of its environmental obligations. As Chapter 4 demonstrated, the precise content of the legal framework for seabed mining, including the framework for the protection of the marine environment from the adverse consequences of seabed mining, was left to be developed by the ISA. In order to do so, the ISA was equipped with law-making powers.

Utilising these powers, the ISA is continuously developing the Mining Code, a collective term for the regulations, recommendations, and related decisions that sets out the detailed rules, regulations, and procedures for prospecting, exploration, and exploitation of deep seabed minerals in the Area. The Mining Code thus represents the manifestation of the ISA's interpretation of its environmental mandate under the United Nations Convention on the Law of the Sea (LOSC or Convention) ${ }^{2}$ and the Agreement Relating to the Implementation of

1 James Harrison, Making the Law of the Sea: A Study in the Development of International Law (Cambridge University Press, 2011), page 137.

2 United Nations Convention on the Law of the Sea (adopted 10 December 1982, entered into force 16 November 1994) 1833 UNTS 3. 
Part XI of the United Nations Convention on the Law of the Sea (IA), ${ }^{3}$ in line with developments in international law, including the need to apply the precautionary principle. In adopting the Mining Code, the ISA develops its obligations further and adds specific environmental measures and standards that can integrate findings from scientific research. Thus, adoption of the Mining Code represents the first step in the ISA's implementation of its environmental mandate. However, implementation does not stop there. As discussed in Chapter 2.1, implementation of the precautionary principle requires more than its mere inclusion into policy or legislative schemes. ${ }^{4}$ Effective implementation of the precautionary principle also requires its application in practice through procedural, institutional and protective measures. Part III of this study analyses, in detail, the manner in which the ISA is implementing precaution in practice. By way of precursor, this chapter focuses on the prior issue which is an examination of the manner in which the ISA is developing the 'legislative aspects' of its environmental mandate through the exercise of its law-making powers.

The chapter begins with a discussion of the ISA's law-making powers in Section 5.2. Section 5.3 then introduces the Mining Code including the future exploitation regulations currently being developed. The core analysis, in Section 5.4, examines the extent to which the ISA has developed its environmental obligations through the Mining Code by analysing the specific environmental measures integrated into the Mining Code. The analysis finishes by demonstrating how the precautionary approach has been specifically incorporated into the Mining Code and examining the precautionary thresholds applicable in the ISA context.

\subsection{Law-making Powers of the ISA}

Adopting the Mining Code is the primary process through which the ISA can develop the seabed mining regime. This core competence was foreseen from the start of negotiating the regime. The 1970 Draft United Nations Convention on the International Sea-Bed Area, submitted by the Us, foresaw that the International Seabed Resource Authority shall prescribe Rules and

3 Agreement Relating to the Implementation of Part XI of the United Nations Convention on the Law of the Sea (adopted 28 July 1994, entered into force 28 July 1996) 1836 UnTs 3.

4 Elizabeth Fisher, Judith S. Jones, and René von Schomberg, 'Implementing the Precautionary Principle: Perspectives And Prospects' in Elizabeth Fisher, Judith S. Jones, and René von Schomberg (eds), Implementing the Precautionary Principle: Perspectives And Prospects (Edward Elgar Publishing, 2006) 1-16, page 1. 
Recommended Practices $[\ldots]$ to ensure $[. .].[t]$ he protection of the marine environment against pollution arising from exploration and exploitation activities. ${ }^{5}$

Building on these early suggestions, the LOSC requires the ISA to adopt rules, regulations, and procedures for all aspects of prospecting, exploration, and exploitation in the Area, ${ }^{6}$ including the effective protection of the marine environment. ${ }^{7}$ Furthermore, the ISA must adopt rules, regulations, and procedures for its financial management and internal administration ${ }^{8}$ and for the equitable sharing of the financial benefits of seabed mining. ${ }^{9}$

The role of these rules, regulations and procedures is to concretise the legal framework provided by the LOSC and general international law by providing specific and detailed content to the general obligations. Moreover, owing to their binding nature, these rules, regulations and procedures are themselves a source of law and legal obligations. In addition, because of their authoritative status, the environmental standards they set also become benchmarks for domestic legislation on seabed mineral mining in areas under national jurisdiction. ${ }^{10}$

During the ISA Preparatory Commission negotiations, the chairman of the working group in charge of developing the draft regulations summarised their role pertinently, stating that the Mining Code 'was a regulatory, not a constitutional document. Although the code may be comprehensive and could be read independently from the Convention, it was not legally independent from the Convention. ${ }^{11}$ A 1984 background paper from the Secretariat of the Preparatory Commission stated this even more clearly:

In the formulation of these rules, regulations and procedures, the primary objective should be to enable the Authority to better carry into effect the provisions of the Convention relating to the conduct of activities in the Area. The rules, regulations and procedures are subsidiary and supplementary to the Convention and are required to be drafted in

5 UNGA, UN Doc A/Ac.138/25 (3 August 1970), article 23.

6 LOSC, articles 137(2), 16o(2)(f),(ii) 162(2)(o)(ii), 209, annex III article 17(1). For a detailed discussion on the law-making powers of the ISA, see Harrison (n. 1), pages 122-146.

$7 \quad$ LOSC, article 145 .

8 LOSC, articles $160(2)(\mathrm{f})(\mathrm{ii}), 162(2)(\mathrm{o})(\mathrm{ii})$.

9 LOSC, articles 82, 16o(2)(f)(i), 162(2)(o)(i).

$10 \quad$ LOSC, article 208.

11 Preparatory Commission for the ISA and ITLOS, LOS/PCN/L.16 (2 April 1985), paragraph 3. 
greater detail and structured in such a way that they become in fact the day-to-day working instruments of the Authority. ${ }^{12}$

In implementing these provisions, the ISA adopts two types of documents, legally binding regulations and non-binding recommendations, which form part of the Mining Code. Although their distinction is discussed in detail in Section 5.3 below, it is necessary to differentiate them at this point because the following analysis explores the ISA's mandate to adopt binding regulations.

ISA regulations are significant in that they are legally binding on all member states. It is a general rule of international institutional law that international organisations (IOs) can only take binding external decisions, meaning those that 'extend beyond the mere functioning of the organization itself,'13 if their constitutions expressly provide for it. ${ }^{14}$ However, the formulations in constituent treaties are often ambiguous ${ }^{15}$ and are not made clearer by the fact that IOs differ widely with respect to the binding character of their external decisions. ${ }^{16}$ In the case of the ISA, the legally binding nature of its regulations is articulated in Articles 137 and 153:

All rights in the resources of the Area are vested in mankind as a whole, on whose behalf the Authority shall act. These resources are not subject to alienation. The minerals recovered from the Area, however, may only be alienated in accordance with this Part and the rules, regulations and procedures of the Authority. ${ }^{17}$

Activities in the Area shall be organized, carried out and controlled by the Authority on behalf of mankind as a whole in accordance with this article as well as other relevant provisions of this Part and the relevant Annexes, and the rules, regulations and procedures of the Authority. ${ }^{18}$

These provisions enable the ISA to adopt detailed terms of seabed mining that are binding on the ISA, sponsoring states, and contractors.

\footnotetext{
12 Preparatory Commission for the ISA and ITLOS, LOS/PCN/SCN.3/WP.1 (8 March 1984), paragraph 2.

13 Henry G. Schermers and Niels M. Blokker, International Institutional Law (vol. 5, Martinus Nijhoff Publishers, 2011), page 766.

14 Ibid., page 825 .

15 Ibid., pages $823-828$.

16 Ibid., page 838 .

17 LOSC, article 137(2) (emphasis added).

18 LOSC, article 153(1) (emphasis added).
} 
This is significant because, as Schermers and Blokker observe in their comprehensive study on international institutions, '[f]ew constitutions allow international organizations to take binding external decisions. ${ }^{19}$ Some IOs are mandated to make decisions that are binding on all parties, except on those who raise objections. For example, the World Health Organization (wHO) can adopt regulations including on sanitary and quarantine requirements to prevent the spread of disease, international names for diseases, and standards for diagnostic procedures for international use. ${ }^{20}$ These become binding on members unless they object within a certain timeframe. ${ }^{21}$ Similar procedures apply for the International Commission for the Conservation of Atlantic Tunas ${ }^{22}$ and the International Whaling Commission. ${ }^{23}$ However, given the discretion for members, these decisions 'more closely resemble conventions with a negative ratification procedure $[\ldots]$ than binding acts of the organization. ${ }^{24} \mathrm{~A}$ similar evaluation may apply to the consultative meetings of the parties to the London Dumping Convention and the 1996 Protocol $^{25}$ that can adopt amendments to the annexes to the London Dumping Convention. Such amendments are binding after a certain period of time except for those parties that declare 'that they are not able to accept the amendment at that time. ${ }^{26}$

In general, it can be observed that the reason for some international organisations possessing law-making powers is to avoid the possibly severe consequences of sub-standard or non-compliant conduct by individual states and their nationals. ${ }^{27}$ Examples include the wHO and the International Civil Aviation Organization (ICAO). The latter has a mandate to establish rules on

19 Schermers and Blokker (n. 13), page 825. See also Jan Klabbers, An Introduction to International Institutional Law (Cambridge University Press, 2009), pages 187, 200. Constitution of the World Health Organization (as amended), (adopted 22 July 1946, entered into force 7 April 1948) 14 UNTS 185, article 21.

21 Ibid., article 22.

22 International Convention for the Conservation of Atlantic Tunas (adopted 14 May 1966, entered into force 21 March 1969) 673 UNTs 63, article viII.

23 International Convention for the Regulation of Whaling (adopted 2 December 1946, entered into force 10 November 1948) 161 UNTS 72, article V(3).

24 Schermers and Blokker (n. 13), pages 794-795.

251996 Protocol to the Convention on the Prevention of Marine Pollution by Dumping of Wastes and Other Matter (adopted 7 November 1996, entered into force 24 March 2006) 36 ILM 1.

26 Convention on the Prevention of Marine Pollution by Dumping of Wastes and Other Matter (adopted 29 December 1972, entered into force 30 August 1975) 1046 UNTS 120, article $\mathrm{Xv}(2)$; see also the amendment procedure in Article 16 of the International Convention for the Prevention of Pollution from Ships (adopted 2 November 1973, entered into force 2 October 1983) 1340 UNTS 184.

27 Christopher W. Pinto, 'The United Nations Convention on the Law of the Sea: Sustainable Development and Institutional Implications' in Peter Bautista Payoyo (ed) Ocean 
aircraft flight and manoeuvring over the high seas. ${ }^{28}$ Moreover, it is authorised to adopt international standards and recommended practices inter alia for air navigation and air traffic control. ${ }^{29}$ However, even the ICAO's founding agreement, the Chicago Convention, leaves room for parties to opt out by notifying the organisation immediately if it they find it impracticable' to comply with the measures. ${ }^{30}$

In contrast, ISA regulations are binding on all members without requiring individual consent and, more importantly, without the possibility for members to opt out. This is despite the fact that the regulations are drafted by the Legal and Technical Commission and adopted by the Council, in which a mere 36 out of over 160 member states can vote. Even though the regulations then have to be approved by the Assembly, in which all member states are represented and decisions are aimed to be taken by consensus, there is an option to ultimately adopt the regulations by majority vote. ${ }^{31}$ These unusual and farreaching competencies for an IO have been described as 'an unprecedented experiment in international law-making.' ${ }^{32}$

It must be noted that ISA regulations are binding on the ISA, contractors, and all member states regardless of their potential integration into domestic law. In contrast, decisions by the Organisation for Economic Co-operation and Development (OECD), for example, are not binding on any member 'until it has complied with the requirements of its own constitutional procedures. ${ }^{33}$ Nonetheless, if a member state sponsors a contractor under the ISA regime, the state has a due diligence obligation to ensure that the contractor complies with its obligations, which includes taking domestic legislative and administrative measures. ${ }^{34}$ Such measures are not a prerequisite to obtaining an exploration

governance: Sustainable Development of the Seas (United Nations University Press, 1994) $3^{-27}$, page 14 .

28 Convention on International Civil Aviation (adopted 7 December 1944, entered into force 4 April 1947) 15 UnTS 295, article 12.

29 Ibid., articles $37,54$.

$30 \quad$ Ibid., article 38; José E. Alvarez, International Organizations as Law-Makers (Oxford University Press, 2005), page 223; Frederic L. Kirgis, International Organizations in Their Legal Setting (2nd ed, West Publishing, 1993), pages 303-309.

31 Chapter 3.5.1.

$32 \quad$ Harrison (n. 1), pages 151-152.

33 Convention on the Organisation for Economic Co-Operation and Development (adopted 14 December 1960, entered into force 30 September 1961) 888 UNTS 179, article 6(2).

34 Responsibilities and Obligations of States Sponsoring Persons and Entities with Respect to Activities in the Area (Advisory Opinion) (Seabed Disputes Chamber, Case No. 17, 1 February 2011) (SDC Advisory Opinion), paragraphs 213-226. 
contract with the ISA, but they are necessary to exempt the sponsoring state from liability for non-compliance under international law. ${ }^{35}$

The ISA's exceptional law-making competencies must be understood in the context of its mandate to give effect to the common heritage of mankind. Its role differs from that of other international organisations, which take decisions that affect the activities of governments, including within their jurisdictional zones, or the way in which states conduct their international relations; be it by determining which air traffic control signals should be used or setting standards to reduce marine pollution. In contrast, the ISA was established as the custodian or, as Pardo denoted it, the 'trustee' ${ }^{36}$ of the mineral wealth in areas beyond the jurisdiction of any single state. The ISA must represent not only its member states but act on behalf of mankind as a whole. Moreover, it focuses on a specific geographical area and determines the standards that must be complied with in order to access and mine minerals in that area. ${ }^{37}$ If any single state could opt out of these standards, it would compromise the integrity of the common heritage of mankind.

In summary, the ISA possesses extensive and significant law-making powers. With its far-reaching competencies to adopt legally binding regulations the ISA can substantially influence the legal regime for seabed mining in the Area, within the framework established by the LOSC and the IA. These powers provide the ISA with the flexibility to develop the legal regime in line with advances in marine sciences and mining technology. Moreover, the ISA's lawmaking powers enable the legal regime to adapt to changes in international law and in social attitudes towards the parameters of mining this common heritage of humankind.

\section{$5 \cdot 3$}

\section{The Mining Code}

Utilising its law-making powers the ISA has been developing the Mining Code. This section introduces both the regulations and recommendations that form

35 Ibid., paragraph 219.

36 UNGA, UN Doc A/C.1./PV.1516 (1 November 1967), paragraph 8.

37 Boyle describes the character of the ISA's work as 'international resource management': Alan E. Boyle, 'Saving the World-Implementation and Enforcement of International Environmental Law through International Institutions' (1991)3(2)Journal of Environmental Law 229-245, page 240 . 
part of the Mining Code, which have been adopted by the ISA and those that are currently being developed.

\subsubsection{Exploration Regulations}

As of July 2016, the ISA has adopted three sets of regulations: Nodules Exploration Regulations, ${ }^{38}$ Sulphides Exploration Regulations, ${ }^{39}$ and Crusts Exploration Regulations ${ }^{40}$ in 2000, 2010, and 2012 respectively. Each set of Regulations contains broadly similar provisions with some differences to account for the distinctive characteristics of each type of deposit. While Part I defines the terms used in the Regulations, Part II specifies rules regarding prospecting. Part III describes the process of applying for an exploration contract and sets out the requirements for applications and the assessment thereof. Part IV addresses exploration contracts with the provisions closely following Annex III to the Losc. Part v forms the focus of this chapter as it enunciates rules on the protection and preservation of the marine environment. The remaining parts of the Regulations address confidentiality issues (Part VI), general procedures (Part VII), dispute settlement (Part VIII), a provision excluding exploration rights over resources other than those that are the focus of the Regulations (Part IX), and review options (Part X).

Importantly, the 'Contract for exploration' and the 'Standard clauses for exploration contract' are annexed to the Regulations. These basic terms apply to all contractors who obtain an exploration contract under the Regulations. However some important differences between the contractors' obligations remain. Notably, the five-year programme of activities, which is not publicly available, is individually developed by each contractor and annexed to the contract. ${ }^{41}$ This programme sets out the specific activities the contractor will undertake in the following 5 -year period and is revised thereafter. Each exploration contract is 15 -years and comprises three programmes of activities. ${ }^{42}$

38 Regulations on Prospecting and Exploration for Polymetallic Nodules in the Area, ISBA/6/A/18 (13 July 2000), amended by ISBA/19/C/17 (22 July 2013), ISBA/19/A/12 (25 July 2013), and ISBA/20/A/9 (24 July 2014) (Nodules Exploration Regulations).

Regulations on Prospecting and Exploration for Polymetallic Sulphides in the Area, ISBA/16/A/12/Rev.1 (15 November 2010), amended by ISBA/19/A/12 (25 July 2013) and ISBA/20/A/10 (24July 2014) (Sulphides Exploration Regulations).

Regulations on Prospecting and Exploration for Cobalt-rich Ferromanganese Crusts in the Area, ISBA/18/A/11 (27 July 2012), amended by ISBA/19/A/12 (25 July 2013) (Crusts Exploration Regulations).

41 Exploration Regulations, annex III schedule 2.

42 Nodules Exploration Regulations, regulation 28; Sulphides and Crusts Exploration Regulations, regulation 30. 
Furthermore, contractors that obtained their respective exploration contracts in different years can be bound by different clauses. This is because both the standard clauses and the Exploration Regulations themselves are specifically incorporated into the contract. ${ }^{43}$ As a result, if the Regulations are amended, these amendments do not apply to existing contractors, as they enjoy security of tenure pursuant to Article 153(6) LOSC. Contracts can only be revised with the consent of both the contractor and the ISA. ${ }^{44}$ As discussed in Chapter 7.3, this is problematic with respect to the ISA's ability to require contractors to observe particular environmental standards.

Regulations can be amended as specifically provided for in Article 165(2)(g) LOsC, which requires the Legal and Technical Commission to keep the rules, regulations, and procedures under review and recommend amendments to the Council 'as it may deem necessary or desirable.' The Regulations themselves require that they be reviewed after 5 years or at any time 'if, in the light of improved knowledge or technology, it becomes apparent that the Regulations are not adequate. ${ }^{45}$ Amendments to the Regulations follow the same procedures as for the adoption of new regulations. ${ }^{46}$ Pursuant to this procedure, the Nodules Exploration Regulations were amended in 2013, to bring them in line with the more recent Exploration Regulations for sulphides and crusts, and particularly the more rigorous environmental standards set therein. ${ }^{47}$ In order to align the three sets of Exploration Regulations, amendments were made in 2014 to the provision on application fees in the Sulphides Exploration Regulations ${ }^{48}$ and the anti-monopoly clause in the Nodules Exploration Regulation. ${ }^{49}$

This clearly demonstrates the flexibility incorporated into the regulatory design, to ensure the seabed mining regime develops alongside new realities in ocean sciences, mining standards, social values, and international (environmental) law.

\subsubsection{LTC Recommendations}

Although not specifically provided for in the LOSC, the ISA develops nonbinding recommendations in addition to its legally binding regulations in

\footnotetext{
43 Exploration Regulations, annex IV clause 1.

44 LOSC, annex II article 19; Exploration Regulations, annex IV section 24.

45 Nodules Exploration Regulations, regulation 42; Sulphides and Crusts Exploration Regulations, regulation 44.

46 Chapter 3.5.1.

47 ISA, ISBA $/ 19 / \mathrm{C} / 7$ (9 April 2013).

48 ISA, ISBA/20/A/10 (24 July 2014).

49 ISA, ISBA/20/A/9 (24 July 2014).
} 
order to implement its law-making mandate. The difference is clearly stated in the standard terms for exploration contracts, which require contractors to 'comply' with the relevant Exploration Regulations, while only requiring them to 'observe, as far as reasonably practicable, any recommendations which may be issued from time to time by the Legal and Technical Commission. ${ }^{50}$ These recommendations are of a technical or administrative nature and provide a greater level of detail regarding the obligations of contractors, such as specifying the data to be collected by contractors in order to implement their obligation to establish environmental baselines at a potential mine site. As such, the recommendations can assist contractors in implementing the ISA's regulations. ${ }^{51}$

Although these recommendations are non-binding, they offer important guidance on what is expected of contractors. In practice, they carry significant weight, not least because the same body that issues the recommendations also decides on whether to recommend approval of a new application for a mining contract. ${ }^{52}$

Interestingly, the competence to develop such recommendations rests exclusively with the Legal and Technical Commission (LTC). Once adopted by the LTC, the recommendations must be reported to the Council, although the latter has no direct power to annul or amend recommendations. The Council may merely 'request' modifications or withdrawal if it finds a recommendation to be inconsistent with the intent and purpose of the corresponding regulations. ${ }^{53}$ Nevertheless, as Harrison highlights, once the Council makes such a request, the recommendations 'will lose much of their persuasive authority and there will be less incentive for investors to comply with them. ${ }^{, 54}$

The first set of such recommendations was issued in 2002 and focused on assessing the possible environmental impacts arising from exploration work for polymetallic nodules. ${ }^{55}$ The 2002 Recommendations were revised in $2010^{56}$ and subsequently developed further to incorporate exploration work for all three types of mineral deposits. Consequently, in 2013, the LTC adopted the Recommendations for the guidance of contractors for the assessment of the

\footnotetext{
50 Exploration Regulations, annex IV section 13.2.

$5^{1} \quad$ Nodules Exploration Regulations, regulation 39(1); Sulphides and Crusts Exploration Regulations, regulation 41(1).

$5^{2} \quad$ Harrison (n. 1), pages 141.

53 Nodules Exploration Regulations, regulation 39(2); Sulphides and Crusts Exploration Regulations, regulation 41(2).

$54 \quad$ Harrison (n. 1), page 142.

55 ISA, ISBA/7/LTC/1/Rev.1** (13 February 2002).

56 ISA, ISBA/16/LTC/7 (2 November 2010).
} 
possible environmental impacts arising from exploration for marine minerals in the Area (EIA Recommendations). ${ }^{57}$ The EIA Recommendations inter alia define the biological, chemical, geological and physical components which contractors have to sample and measure to establish environmental baselines, ${ }^{58}$ and identify activities that require environmental impact assessment (EIA) ${ }^{59}$ and those that do not require EIA. ${ }^{60}$ The EIA Recommendations also suggest that specific guidelines will be developed on several other environmental protection measures in the future. ${ }^{61}$

In 2015, the LTC adopted Recommendations for the Guidance of Contractors on the Content, Format and Structure of Annual Reports. ${ }^{62}$ These complement the EIA Recommendations by requiring contractors to provide information on inter alia ecosystem functioning as well as comparisons of their findings with published data from other studies. ${ }^{63}$ Further recommendations have been adopted with regards to the obligation of contractors to offer training programmes ${ }^{64}$ and to report on financial expenditure. ${ }^{65}$

\subsubsection{Future Exploitation Regulations}

In addition to the existing instruments that form part of the Mining Code, preliminary work on the first regulations for the exploitation of seafloor minerals commenced in $2011 .{ }^{66}$ In carrying out the considerable task of developing this comprehensive framework for the commercial-scale exploitation of minerals, the ISA issued a workplan for the formulation of the exploitation regulations ${ }^{67}$ and commissioned a technical scoping study that provides a comparative analysis of the core features of land-based mineral mining frameworks. ${ }^{68}$ In 2014, the ISA also conducted an initial stakeholder survey to seek input

57 ISA, ISBA/19/LTC/8 (1 March 2013).

58 Ibid., paragraphs 14-16.

59 Ibid., paragraph 19.

6 o Ibid., paragraph 18.

$61 \quad$ Nodules Exploration Regulations, regulations 18(b), 31(3)-(4), 32; Sulphides and Crusts Exploration Regulations, regulations 20(1)(b), 33(3)-(4), 34.

62 ISA, ISBA/21/LTC/15 (4 August 2015).

63 Ibid., annex I paragraph 9.

64 ISA, ISBA/19/LTC/14 (12 July 2013).

65 ISA, ISBA/21/LTC/11 (14 April 2015).

66 ISA, ISBA $/ 17 / \mathrm{C} / 21$ * (21 July 2011), paragraph 20.

67 ISA, ISBA/18/C/4 (25 April 2012).

68 Allen L. Clark, Jennifer Cook Clark, and Sam Pintz, Towards the Development of a Regulatory Framework for Polymetallic Nodule Exploitation in the Area (Technical Study No. 11) (ISA, 2013). 
regarding the development of the Mining Code. ${ }^{69}$ In March 2015, taking into account the survey responses, the IsA published a first draft framework for the regulation of exploitation activities in the Area ${ }^{70}$ as well as a Discussion Paper on the Development and Implementation of a Payment Mechanism in the Area. ${ }^{71}$ Stakeholder feedback on both documents was invited and a revised draft framework was published in July 2015. ${ }^{72}$ Stakeholder input was also invited for a first working draft of the exploitation regulations, which was released in July 2016.73

From the outset, it was clear that environmental protection measures will be 'amongst the most important elements of such a framework' 74 for the exploitation of minerals. While mineral exploration work can pose serious environmental risks, ${ }^{75}$ particularly because it includes test mining, the most serious environmental impacts are expected to occur during exploitation work. This was reflected in discussions in the Legal and Technical Commission for the development of the Sulphides and Crusts Exploration Regulations: 'While environmental considerations were discussed at length, there was agreement that greater attention is required when granting exploitation licenses rather than when granting exploration licenses and that, as such, some of the more critical questions could be addressed at a later date. ${ }^{76}$ Indeed the 2013 ISA Technical Study argued that ' $[t]$ here will be a need for ISA to develop a separate set of environmental regulations governing mining. ${ }^{77}$

The study also discusses the option of offering 'retention licenses' for those explorers who have to postpone their application for exploitation rights for various reasons. A retention license would enable them to retain exclusive

69 ISA, Developing a Regulatory Framework for Mineral Exploitation in the Area: Stakeholder Engagement (February 2014) <http://www.isa.org.jm/files/documents/EN/Survey/ISASSurvey.pdf>.

70 ISA, ISBA/Cons/2015/1 (March 2015).

71 Ibid.

72 ISA, Developing a Regulatory Framework for Deep Sea Mineral Exploitation in the Area: Draft Framework, High Level Issues and Action Plan, Version II, (15 July 2015) <https://www .isa.org.jm/files/documents/EN/OffDocs/Rev_RegFramework_ActionPlan_14072015.pdf >.

73 ISA, Developing a Regulatory Framework for Mineral Exploitation in the Area: Report to Members of the Authority and All Stakeholders (July 2016) <https://www.isa.org.jm/files/ documents/EN/Regs/DraftExpl/Draft_ExplReg_SCT.pdf > .

74 ISBA $/ 18 / \mathrm{C} / 4$ (n. 67), paragraph 5 .

75 EIA Recommendations (n. 57), paragraph 9.

76 ISA, ISBA/10/C/4 (28 May 2004), paragraph 15.

77 Clark, Cook Clark, and Pintz (n. 68), page 33. 
exploration rights in return for payment. ${ }^{78}$ However, this could provide incentives to obtain several exploration contracts early to reserve areas with highgrade mineral deposits and prevent others from accessing them. Again, the ISA has not yet addressed retention licenses.

Given that the development of exploitation regulations will require some time yet, but the first 15-years exploration contracts expired in 2016, the ISA has adopted Procedures and Criteria for the Extension of an Approved Plan of Work for Exploration..$^{79}$ These allow extensions of exploration contracts of no more than five years, provided the contractor can demonstrate that for reasons beyond his control he was rendered unable to complete the exploration work, or that the prevailing economic circumstances do not justify proceeding to the exploitation stage. ${ }^{80}$ Moreover, the contractor must submit the data and results obtained during exploration work, including a table summarising all environmental baseline data collected in accordance with the EIA Recommendations, which is then reviewed by the Legal and Technical Commission. ${ }^{81}$ In July 2016, the first six exploration contracts, which expired in 2016, were extended for 5 years.

\subsection{The ISA's Environmental Obligations as Developed by the Mining Code}

As this study has demonstrated, the LOSC and the IA set the legal framework for the seabed mining regime and equip the ISA with a comprehensive environmental mandate. They also confer law-making powers upon the ISA to develop the seabed mining regime and fill the gaps left by the founding agreements. Building on these powers, the ISA has been developing the Mining Code.

An important element of the Mining Code is to develop specific environmental standards and protective measures. This was already foreseen during the work of the Preparatory Commission, when the Group of Technical Experts stated:

The Group wishes to draw the attention of the Preparatory Commission to the importance of the environmental protection provisions of modern regulatory regimes. [...] This part of the deep seabed mining regime

\footnotetext{
78 Ibid., pages 29-31.

79 ISA, ISBA/21/C/19 (23 July 2015).

8 Ibid., appendix I.

81 Ibid., annex paragraph 9, appendix I.
} 
has yet to mature and there are many details and procedures to be worked out. ${ }^{82}$

Responding to this necessity, Part $\mathrm{v}$ of the Exploration Regulations addresses environmental protection. However, as the then Head of the Office of Legal Affairs at the ISA Secretariat observed in relation to the Nodules Exploration Regulations:

The provisions relating to the protection and preservation of the marine environment were among the most controversial [provisions] to be addressed during the process of negotiation of the Regulations. Whilst, on the one hand, contractors and potential contractors strongly preferred an incremental approach to environmental regulation, with an emphasis on the need to gather more data during the exploration phase, other participants in the negotiations considered there was a need to take a precautionary approach to any activities from the outset. Ultimately, what is contained in the Regulations is somewhat of a mixture of the two approaches. ${ }^{83}$

This mixture is explored in the remainder of this chapter and in Chapter 7.3.

The environmental provisions in the Exploration Regulations can broadly be divided into the following five categories. First, the Regulations reiterate the obligation of the ISA to actively develop and implement environmental protection standards and to keep them under review. ${ }^{84}$ Second, they identify applicable principles, such as the need to apply the precautionary approach. ${ }^{85}$ Third, the Regulations extend the environmental obligations of states and the ISA to contractors, including private entities, who are not directly bound by the Losc. The Regulations require that 'each contractor shall take necessary measures to prevent, reduce and control pollution and other hazards to the

82 Preparatory Commission for the ISA and ITLOS, LOS/PCN/BUR/R.32 (1 February 1994), paragraph 29.

83 Michael W. Lodge, 'Environmental Regulation of Deep Seabed Mining' in Andree Kirchner (ed), International Marine Environmental Law: Institutions, Implementation and Innovations (Kluwer Law International, 2003) 49-59, page 54.

84 Nodules Exploration Regulations, regulation 31(1); Sulphides and Crusts Exploration Regulations, regulation 33(1); Chapter 4.3.2.

85 Nodules Exploration Regulations, regulations 2(2), 5(1), 31(2)-(3); Sulphides and Crusts Exploration Regulations, regulations 2(2), 5(1), 33(2)-(3). 
marine environment arising from its activities in the Area [...].86 In order to give effect to this general obligation, each contractor must establish environmental baselines against which to assess the environmental impacts of his work, and a monitoring programme to continuously identify environmental challenges. ${ }^{87}$ Fourth, they set out specific, substantive protection measures, such as establishing protected areas and requiring best environmental practices. ${ }^{88}$ Lastly, the Regulations set out further details regarding the ISA's compliance and enforcement competencies ${ }^{89}$ as well as the liability of each contractor for environmental damage. ${ }^{90}$

It will be recalled that Article 145 LOSC mandates the ISA to take 'necessary measures' to give effect to its environmental mandate. The aforementioned provisions of the Exploration Regulations, together with the EIA Recommendations provide some guidance as to the meaning of 'necessary measures.' ${ }^{91}$ Nevertheless, these will likely change over time. In this context, when working on the Exploration Regulations for sulphides and crusts, the working group on environmental issues within the Legal and Technical Commission 'considered that it was appropriate [...] to reflect in the draft regulations the developments in international environmental law achieved since the adoption of the Convention in $1982 .{ }^{92}$ This evolutionary approach to environmental standards was also supported by the Seabed Disputes Chamber's Advisory Opinion ${ }^{93}$ and it is envisaged in the Exploration Regulations themselves, which provide for further supplementary rules, regulations and procedures, 'in particular on the protection and preservation of the marine environment. ${ }^{94}$

86 Nodules Exploration Regulations, regulation 31(5); Sulphides and Crusts Exploration Regulations, regulation 33(5).

87 Nodules Exploration Regulations, regulation 32; Sulphides and Crusts Exploration Regulations, regulation 34.

88 Nodules Exploration Regulations, regulation 21(6), 31(5); Sulphides and Crusts Exploration Regulations, regulations 23(6), 33(5); Chapters 5.4.2, 5.4.3.

89 Nodules Exploration Regulations, regulation 33; Sulphides and Crusts Exploration Regulations, regulation 35 .

90 Nodules Exploration Regulations, regulation 30; Sulphides and Crusts Exploration Regulations, regulation 32.

91 Satya N. Nandan, Michael W. Lodge, and Shabtai Rosenne, United Nations Convention on the Law of the Sea, 1982: A Commentary, Volume VI (Martinus Nijhoff Publishers, 2002) page 198.

92 ISA, ISBA $/ 9 / \mathrm{C} / 4$ (1 August 2003), paragraph 7.

93 SDC Advisory Opinion, paragraphs 136-137; Chapter 4.4.

94 Exploration Regulations, regulation 1(5). 
In sum, adopting and revising the Mining Code is a crucial way in which the ISA gives shape to its environmental mandate. The following sections explore in detail the aforementioned categories of environmental provisions. They sets out the specific obligations with respect to environmental impact assessments, monitoring of environmental effects, marine protected areas, best environmental practices, emergency orders and environmental liabilities, and of course, the obligation to apply the precautionary principle. The latter is reserved for the final section of this Chapter as it builds the foundation for and leads into to Part III of this study.

\subsubsection{Assess and Monitor Environmental Impacts}

The LOSC sets out the general obligation to prevent, reduce and control pollution and other hazards to the marine environment arising from seabed mining activities. ${ }^{95}$ The ISA extended this obligation to contractors ${ }^{96}$ and developed it further by requiring each contractor to carry out three distinct yet related tasks, namely to establish environmental baselines, carry out environmental impact assessments, and continuously monitor the effects of its activities on the marine environment. Each of these obligations is discussed individually in the following sections.

\subsubsection{Environmental Baselines}

The necessity for environmental baselines against which the environmental effects of seabed mining activities can be assessed was first specifically stated in the IA. Section 1(7) of the Annex to the IA requires that every application 'for approval of a plan of work shall be accompanied by [...] a description of a programme for oceanographic and baseline environmental studies in accordance with the rules, regulations and procedures adopted by the Authority. The Exploration Regulations incorporate this requirement and specifically add that the baseline data has to enable an assessment of the impacts of the proposed activities on biodiversity. ${ }^{97}$ Moreover, the Regulations oblige every contractor to generally gather environmental baseline data and establish environmental baselines. ${ }^{98}$

\footnotetext{
95 LOSC, articles 194-196, 208-209.

$96 \quad$ Nodules Exploration Regulations, regulation 31(5); Sulphides and Crusts Exploration Regulations, regulation 33(5).

97 Nodules Exploration Regulations, regulation 18(b); Sulphides and Crusts Exploration Regulations, regulation 24(b).

98 Nodules Exploration Regulations, regulation 32; Sulphides and Crusts Exploration Regulations, regulation 34 .
} 
The EIA Recommendations, adopted by the Legal and Technical Commission, further specify the obligations by describing the procedure to be followed in the acquisition of baseline data and the data to be collected, ${ }^{99}$ including data relating to 'physical, chemical, biological and other parameters that characterize the systems likely to be impacted by exploration and possible test-mining activities. ${ }^{100}$ Moreover, the Recommendations require that the 'best available technology and methodology for sampling should be used in establishing baseline data for environmental impact assessments.'101 The annex to the Recommendations refers contractors to specific organisations that have developed best practices for data collection and analytical techniques. ${ }^{102}$

Importantly, the standard terms for exploration contracts specifically state that prior to the commencement of exploration activities, the contractor must submit '[d]ata that could be used to establish an environmental baseline against which to assess the effect of the proposed activities. ${ }^{\prime 103}$ As such, the establishment of environmental baselines is not only a contractual obligation but also a prerequisite for commencing exploration activities.

However, the Mining Code is unclear with respect to the specific point in time at which a contractor must submit such baseline data. As noted above, when applying for an exploration contract, a mere description of a programme for baseline studies is sufficient. The exploration contracts then require baseline data 'prior to the commencement of exploration activities.' ${ }^{104}$ However, exploration is defined as including the carrying out of studies of the environmental, technical, economic, commercial and other appropriate factors that must be taken into account in exploitation. ${ }^{\prime 105}$ Consequently, environmental baseline data must be submitted sometime during the lifetime of an exploration contract, yet prior to start of exploration work. Similarly, the EIA Recommendations require contractors 'to provide the Secretary-General' with a 'status of regional and local environmental baseline data,'106 without specifying the point at which the contractor must provide such data. This has proven to be problematic in practice with ISA reports having repeatedly

\footnotetext{
$99 \quad$ EIA Recommendations (n. 57), paragraph 9.

100 Ibid., paragraph 14.

101 Ibid., paragraph 17, see also paragraphs 14-15, 34.

102 Ibid., annex, paragraph 55.

103 Exploration Regulations, annex IV section 5.2.

104 Ibid.

105 Exploration Regulations, Regulation 1(3)(b).

106 EIA Recommendations (n. 57), paragraph 27(q).
} 
called upon contractors to submit the required environmental baseline data. ${ }^{107}$ Given a lack of transparency as discussed in Chapter 7.4, it is unclear whether such data has been submitted. ${ }^{108}$ A lack of baselines, in turn, hinders not only the assessment of environmental impacts but also the development of the regulatory framework for mineral exploitation. This is discussed in detail in Chapter 7.2.3.1.

\subsubsection{Environmental Impact Assessments}

The obligation to perform EIAs for activities that could result in significant harm is an obligation under customary international law. ${ }^{109}$ It is also closely linked to the precautionary principle with both concepts sharing a similar dilemma; although they are widely accepted, their content remains ambiguous. Indeed, the need for a clear framework concerning the scope and content of EIAs is being discussed in the context of developing a new agreement regarding the protection of marine biological diversity in areas beyond national jurisdiction. ${ }^{110}$ Simultaneously, work is underway at the Conference of the Parties of the Convention on Biological Diversity specifically concerning the scientific and technical aspects relevant to EIAs in areas beyond national jurisdiction. ${ }^{111}$

In general terms, an EIA is a process that results in a written report which guides decision-making and has several related functions:

First, it should provide decision-makers with information on the environmental consequences of proposed activities and, in some cases,

107 ISA, ISBA/20/C/20 (16 July 2014), annex I paragraph 12; ISBA/17/C/21* (n. 66), paragraph 13

108 Seascape Consultants, Review of Implementation of the Environmental Management Plan for the Clarion-Clipperton Zone (20 May 2014) <http://isa.org.jm/files/documents/ EN/2oSess/LTC/CCZ-EMPRev.pdf>, page 10; ISBA/Cons/2015/1 (n. 70), page 41.

109 SDCAdvisory Opinion, paragraphs 145, 147-149; Robin Warner, 'Oceans beyond Boundaries: Environmental Assessment Frameworks' (2012) 27 The International Journal of Marine and Coastal Law 481-499.

110 ввNJ Working Group, UN Doc A/68/399 (23 September 2013), paragraph 34; Elisabeth Druel et al., A Long and Winding Road-International Discussions on the Governance of Marine Biodiversity in Areas beyond National Jurisdiction (Studies No. 07/13, IDDRI, 2013), page 18 .

111 CBD, Report of the Expert Workshop on Scientific and Technical Aspects Relevant to Environmental Impact Assessment in Marine Areas Beyond National Jurisdiction, UNEP/ СвD/EW-eiama/2 (20 November 2009); Свр, Marine and Coastal Biodiversity: Revised Voluntary Guidelines for the Consideration of Biodiversity in Environmental Impact Assessments and Strategic Environmental Assessments in Marine and Coastal Areas, UNEP / CBD/COP/11/23 (21 August 2012); Warner (n. 109), pages 484-487. 
programmes and policies, and their alternatives. Second, it requires decisions to be influenced by that information. And, third, it provides a mechanism for ensuring the participation of potentially affected persons in the decision-making process. ${ }^{112}$

With seabed mining being a potentially serious yet under-researched threat to marine biodiversity, EIAs form an important part of the ISA's environmental mandate. The basis of this mandate derives from the LOSC. Article 206 requires assessments of environmental impacts in general terms:

When States have reasonable grounds for believing that planned activities under their jurisdiction or control may cause substantial pollution of or significant and harmful changes to the marine environment, they shall, as far as practicable, assess the potential effects of such activities on the marine environment and shall communicate reports of the results of such assessments in the manner provided in article 205. ${ }^{113}$

This provision applies to all human activities regardless of where they take place. ${ }^{114}$ In addition to the obligation of states, the IA specifically introduced an obligation of future contractors to include an EIA with every application to the IsA for a plan of work. ${ }^{115}$ The Seabed Disputes Chamber highlighted that the obligation of sponsoring states to ensure contractors conduct EIAs is not only a direct obligation under the Exploration Regulations ${ }^{116}$ but also an element of due diligence, ${ }^{117}$ making it applicable beyond the Regulations. ${ }^{118}$

The Convention also obliges the ISA itself to conduct environmental impact assessments. Article $165(2)(d)$ creates a general obligation for the Legal and Technical Commission to 'prepare assessments of the environmental implications of activities in the Area.'119 Interestingly, the Mining Code does not

112 Philippe Sands and Jacqueline Peel, Principles of International Environmental Law (3rd ed, Cambridge University Press, 2012), page 601.

113 LOsc, article 206; see also articles $165(2)(\mathrm{d})-(\mathrm{f})$.

114 Myron H. Nordquist et al., United Nations Convention on the Law of the Sea, 1982: A Commentary, Volume IV (Martinus Nijhoff Publishers, 1991), page 124.

115 IA, annex section $1(7)$.

116 Nodules Exploration Regulations, regulation 31(6); Sulphides and Crusts Exploration Regulations, regulation 33(6).

117 SDC Advisory Opinion, paragraphs 141-145.

118 Ibid., paragraphs 150.

119 See also LOSC, article $165(2)(\mathrm{f})$ which highlights the need to take into account 'assessments of the environmental implications of activities in the Area' when drafting rules, regulations, and procedures for the Council. 
specify details for the implementation of Article 165(2)(d) and the Legal and Technical Commission has not yet prepared any such assessments.

However, the Mining Code has further developed the general obligation on contractors to conduct EIAs, requiring them in two instances. The first assessment is required as part of an application for an exploration contract. However, in contrast to the IA, the Exploration Regulations only require a preliminary EIA at that stage. ${ }^{120}$ While the Legal and Technical Commission can only recommend approval of an application if a preliminary EIA has been submitted, ${ }^{121}$ the meaningfulness of this EIA is questionable. The Mining Code does not specify requirements for this preliminary assessment, and the EIA Recommendations exclude most early stage exploration activities from the need for EIAS. ${ }^{122}$ Moreover, EIAs require environmental baseline data to assess impacts against, yet such data is only gathered later in the process, as discussed in Section 5.4.1.1 and Chapter 7.2.3.1.

Second, contractors must submit a full EIA prior to specific exploration activities. The standard clauses for exploration contracts provide the following:

Prior to the commencement of exploration activities, the Contractor shall submit to the Authority:

(a) An impact assessment of the potential effects on the marine environment of the proposed activities;

(b) A proposal for a monitoring programme to determine the potential effect on the marine environment of the proposed activities; and

(c) Data that could be used to establish an environmental baseline against which to assess the effect of the proposed activities. ${ }^{123}$

While the original Nodules Exploration Regulations, adopted in 2000, only required EIAs prior to test mining, ${ }^{124}$ this was later expanded to apply to all exploration activities. ${ }^{125}$ However, the EIA Recommendations limit this provision again. They identify activities with the potential to cause serious environmental harm, and exclude other exploration activities from the scope of EIAs. As a result, EIAs are specifically required for drilling activities, artificial

\footnotetext{
120 Nodules Exploration Regulations, regulation 18(c); Sulphides and Crusts Exploration Regulations, regulation 20(1)(c).

121 Ibid.

122 EIA Recommendations (n. 57), paragraph 18.

123 Exploration Regulations, annex IV section 5.2.

124 ISA, ISBA/6/A/18 (13 July 2000), annex IV section 5.5.

125 Nodules Exploration Regulations, annex IV section 5.2.
} 
disturbance of the sea floor, specific sampling work, and test mining, ${ }^{126}$ which can be carried out under an exploration contract. ${ }^{127}$ For those activities, contractors are required to provide the ISA with environmental observations and measurements both during and after the specific activity ${ }^{128}$ to establish the extent of the disturbance as well as the rates of recovery. A full EIA is required one year before a contractor commences any of these activities. Consequently, although the Mining Code has developed the obligation to conduct EIAs, it has not necessarily strengthened it. Indeed, the opposite may be argued.

Despite the fact that several exploration contracts entered their 5 -years extension phase in 2016, and exploitation regulations are already being developed, the vast majority of exploration contractors have not yet submitted EIAS. Moreover, since the assessments have to be provided when an exploration contract is already in force, the practical implications of EIAs deserve close attention. Chapters 7.2.3 and 7.3 examine this in detail.

In addition to EIAs, a similar concept called strategic environmental assessment (SEA) must be introduced. SEAs are somewhat less entrenched in international law ${ }^{129}$ but no less relevant, especially in the context of a precautionary approach to seabed mining. The term describes the process of evaluating environmental consequences at an early stage, similar to the precautionary principle, when systems-scale policies or programmes are being developed. ${ }^{130}$ The Protocol on Strategic Environmental Assessment to the Convention on Environmental Impact Assessment in a Transboundary Context, defines SEA as:

the evaluation of the likely environmental, including health, effects, which comprises the determination of the scope of an environmental report and its preparation, the carrying-out of public participation and consultations, and the taking into account of the environmental report

126 EIA Recommendations (n. 57), paragraph 19-21.

127 Exploration Regulations, regulation 1(3).

128 EIA Recommendations (n. 57), paragraphs 19, 29-30.

129 Warner (n. 109), page 489.

130 'Strategic environmental assessment is the formalized, systematic and comprehensive process of identifying and evaluating the environmental consequences of proposed policies, plans or programmes to ensure that they are fully included and appropriately addressed at the earliest possible stage of decision-making on a par with economic and social considerations' (СвD COPo6, Decision VI/7, UNEP/CBD/COP/DEc/Vi/7 (19 April 2002), annex paragraph $1(\mathrm{~b})$ ). 
and the results of the public participation and consultations in a plan or programme. ${ }^{131}$

Consequently, SEA provides an overarching strategic framework within which EIAS for individual projects can be made. They are a necessary requirement for regional marine spatial planning, ${ }^{132}$ including the establishment of marine protected areas.

Given the ISA's mandate to actively develop the Area regime, SEAs could, as Warner notes, 'become a component of discharging the ISA's obligations under Article 145 LOSC' which provides for 'necessary measures [...] to ensure effective protection for the marine environment.'133 Indeed, the Authority's mandate to conduct strategic environmental assessments can be implied by Article 145 and Article 165(2)(d) and (f) LOSC which require the Legal and Technical Commission to 'prepare assessments of the environmental implications' and take them into account when drafting the rules, regulations, and procedures. However, strategic environmental assessments have not yet been incorporated into the Mining Code. The role of these assessments in the procedural framework of the ISA is examined in Chapter 7.2.1.

Closely related to the need for strategic environmental assessments is the integration of cumulative impacts into both SEAS and EIAs. These integrate the assessment of the environmental impacts both from multiple activities, of which seabed mining is only one, and numerous mining operations over large areas and sustained periods. Although cumulative impact assessments are not formally required by the LOSC or incorporated into the Exploration Regulations, the EIA Recommendations provide for the use of environmental baseline data for 'regional environmental management and assessment of cumulative impacts.' 134

A last shortcoming of the current regulatory framework for EIAs is the failure to account for alternatives. EIAs ordinarily include the consideration of feasible alternatives, such as different 'project location, scales, processes, layouts,

131 Protocol on Strategic Environmental Assessment to the Convention on Environmental Impact Assessment in a Transboundary Context (adopted 21 May 2003, entered into force 11 July 2010), Doc ECE/MP.EIA/2003/2, article 2(6).

132 Michael Lodge et al., 'Seabed Mining: International Seabed Authority Environmental Management Plan for the Clarion-Clipperton Zone. A Partnership Approach' (2014) 49 Marine Policy 66-72, page 72.

133 Warner (n. 109), page 491.

134 EIA Recommendations (n. 57), paragraph 16; Chapter 7.2.1. 
operation conditions and the 'no action' option.'135 Similarly, in identifying possible precautionary responses to environmental risks posed by specific activities, the precautionary principle requires consideration of alternatives to such activities. ${ }^{136}$ The relevant question is whether the desired outcome can be achieved through less harmful means. In the seabed mining context, this would comprise assessing the potential environmental impacts of various technologies or methods that form part of the mining process. Could some of these be replaced by safer methods, for example by using different technology or requiring a specific system to dispose of waste and tailings? On a strategic level, such assessment can also extend to the broader question of how to best achieve the level of mineral supply needed, including considering alternatives to seabed mining. This is further discussed in Chapter 7.2.1.

In sum, assessing the environmental impacts of seabed mining activities is a key part of the ISA's mandate. Its implementation in the Mining Code focuses on the requirements for contractors to conduct EIAs during their exploration work. At present, the Exploration Regulations omit strategic environmental assessments and cumulative impact assessments, as well as the assessment of alternatives methods to substitute particularly harmful activities. Additionally, the Exploration Regulations do not specify what action the ISA must take following the receipt of an EIA.

\subsubsection{Monitoring Effects on the Marine Environment}

To complement EIAs, the ISA's mandate also includes the continuous monitoring of seabed mining activities on the marine environment. Article $165(2)(\mathrm{h})$ LOSC requires the Legal and Technical Commission to:

make recommendations to the Council regarding the establishment of a monitoring programme to observe, measure, evaluate and analyse, by recognized scientific methods, on a regular basis, the risks or effects of pollution of the marine environment resulting from activities in the Area,

135 John Glasson, Riki Therivel, and Andrew Chadwick, Introduction to Environmental Impact Assessment (Routledge, 2013), page 5; Roel Slootweg et al., Biodiversity in EIA \& SEA-Background Document to CBD Decision VIII/28: Voluntary Guidelines on BiodiversityInclusive Impact Assessment (Commission for Environmental Assessment, 2006), pages 29-38; Directive 2001/42/EC of the European Parliament and of the Council of 27 June 2001 on the Assessment of the Effects of Certain Plans and Programmes on the Environment, OJ L 197/30, article 5(1).

136 Commission of the European Communities, Communication from the Commission on the precautionary principle, $\operatorname{coM}(2000) 1$ final (2 February 2000), page 17. 
ensure that existing regulations are adequate and are complied with and coordinate the implementation of the monitoring programme approved by the Council.

This monitoring programme corresponds to the general obligation of states, pursuant to Article 204 LOSC, to 'observe, measure, evaluate and analyse [...] the risks or effects of pollution of the marine environment' and to 'keep under surveillance the effects of any activities which they permit or in which they engage in order to determine whether these activities are likely to pollute the marine environment.'

These obligations were developed further through the Mining Code. The Exploration Regulations require contractors to establish a programme for 'monitoring and evaluating the impacts of deep seabed mining on the marine environment.'137 To this end, each plan of work for the exploration of minerals has to consider three phases of environmental studies: (a) environmental baseline studies; (b) monitoring in order to 'ensure that no serious harm is caused to the marine environment from activities during prospecting and exploration'; and (c) monitoring during and after testing collecting systems. ${ }^{138}$ Both prospectors and contractors are required to cooperate with the ISA and the sponsoring state in the establishment and implementation of such monitoring programme. ${ }^{139}$ The programmes require contractors to report annually on the implementation and results of the monitoring programme. ${ }^{140}$ In sum, the monitoring programme should complement the obligation to conduct EIAs. The explanatory note to the EIA Recommendations summarise the linkage:

The environmental studies to be conducted during exploration will include the monitoring of environmental parameters so as to confirm the findings that there is no serious environmental harm from any activities being conducted on the seabed, in mid-water and in the upper water column. ${ }^{141}$

137 Nodules Exploration Regulations, regulations 31(6), 32; Sulphides and Crusts Exploration Regulations, regulations 33(6), 34 .

138 EIA Recommendations (n. 57), paragraph 11.

139 Nodules Exploration Regulations, regulations 5(2), 32(1); Sulphides and Crusts Exploration Regulations, regulations 5(2), 34(1).

140 Nodules Exploration Regulations, regulations 32(2); Sulphides and Crusts Exploration Regulations, regulations 34(2); Exploration Regulations, annex IV sections 5.5, 10.2(a).

141 EIA Recommendations (n. 57), annex I paragraph $5^{0 .}$ 
The programme may, when required by the Council, also include the designation of 'impact reference zones' and 'preservation reference zones.' ${ }^{142}$ The former will be mined, while the latter will provide pristine areas for comparisons of mining impacts and offer refuge for biodiversity. ${ }^{143}$ The practical implementation of these zones presents challenges, as discussed in Chapter 6.3.4. Moreover, the implementation of the monitoring programme in general is examined in Chapter 7.6.

This section has demonstrated that both assessing and monitoring impacts of seabed mining activities on the marine environment form part of the ISA's environmental mandate. To facilitate their implementation, the Mining Code requires contractors to first establish environmental baselines against which to assess and evaluate the impacts. This is particularly important given the inchoate knowledge about deep ocean ecosystems and frontier nature of seabed mining. Interestingly, though, the Mining Code does not develop the ISA's mandate to coordinate, promote, and conduct marine scientific research in the Area, which could further help fill knowledge gaps. The Exploration Regulations place the onus of establishing baselines onto the contractors and are silent with respect to the potential role for the ISA in coordinating collaborative, targeted research projects to establish regional environmental baselines. In this context, the Mining Code could conceivably set out a greater role for the ISA in this respect. ${ }^{144}$

\subsubsection{Marine Protected Areas}

In addition to the obligation to assess and monitor impacts of seabed mining activities on the marine environment, the Mining Code provides for the use of spatial tools to manage and limit adverse environmental impacts from seabed mining. Indeed, as noted in Section 5.4.1, areas in which seabed mining is prohibited as a control measure, then named 'preservation reference zones', are part of the ISA's monitoring programmes.

Marine protected areas ${ }^{145}$ are a core element of marine environmental management and feature strongly in the ongoing debate over the lack of protection

142 Nodules Exploration Regulations, regulations 31(6); Sulphides and Crusts Exploration Regulations, regulations $33(6)$.

143 Ibid.; EIA Recommendations (n. 57), paragraph 26(d).

144 Chapter 6.2.

145 The International Union for Conservation of Nature (IUCN) defines marine protected areas (MPAs) as spaces 'managed, through legal or other effective means, to achieve the long-term conservation of nature with associated ecosystem services and cultural values. Management of MPAs can range from strictly protected nature reserves to multiple use areas managed to achieve a variety of conservation objectives' (N. Dudley (ed) Guidelines for Applying Protected Area Management Categories (IUCN, Gland, Switzerland 2008)). 
of marine biodiversity in areas beyond national jurisdiction. In order to place the obligations of the ISA in context, this section will first provide a brief summary of the discussion over spatial tools for marine biodiversity protection before analysing specifically the scope of the ISA's obligations in this regard.

\subsubsection{Marine Protected Areas in Areas Beyond National Jurisdiction}

The need for a network of representative marine protected areas has been discussed in the context of areas beyond national jurisdiction as one of the main management measures that can help to protect both endemic or sedentary species butalso migratory species by providing feeding and breeding grounds. ${ }^{146}$ Several international instruments have called for the establishment of marine protected areas (MPAS), including the Convention on Biological Diversity, ${ }^{147}$ Agenda 21, ${ }^{148}$ the Aichi Biodiversity Targets, ${ }^{149}$ and the Rio+20 outcome document. ${ }^{150}$ Moreover, the UN General Assembly has repeatedly called upon states and international organisations to integrate MPAs as a tool to protect marine biodiversity. ${ }^{151}$ Indeed, the establishment of marine protected areas 'has been on the political agenda since the beginning of the 1990s.'152

While the importance of marine protected areas is widely accepted, their implementation is hindered by a number of factors. ${ }^{153}$ These include an

146 L.M. Wedding et al., 'Managing Mining of the Deep Seabed' (2015) 349 Science 144-145; Lee A. Kimball, The International Legal Regime of the High Seas and the Seabed Beyond the Limits of National Jurisdiction and Options for Cooperation for the Establishment of Marine Protected Areas (MPAs) in Marine Areas Beyond the Limits of National Jurisdiction (Technical Series No. 19) (Secretariat of the Convention on Biological Diversity, 2005); Kristina M. Gjerde and Anna Rulska-Domino, 'Marine Protected Areas beyond National Jurisdiction: Some Practical Perspectives for Moving Ahead' (2012) 27 The International Journal of Marine and Coastal Law 351-373, page 353; Karen N. Scott, 'Conservation on the High Seas: Developing the Concept of the High Seas Marine Protected Areas' (2012) 27(4) The International Journal of Marine and Coastal Law 849-857.

147 СвD, article 8.

148 Agenda 21, reprinted in UN Doc A/CONF.151/26/Rev.1 (12 August 1992), paragraph 17.86.

149 СBD COP10, Decision $X / 2$, UNEP/CBD/COP/DEC/X/2 (29 October 2010).

150 UNGA, UN Doc A/Res/66/288 (27 July 2012), paragraph 177 .

151 UNGA, Un Doc A/REs/68/70 (9 December 2013), paragraphs 208-213; UNGA, UN Doc A/ $\operatorname{RES} / 63 / 111$ (5 December 2008), paragraph 134.

152 Erik J. Molenaar and Alex G. Oude Elferink, 'Marine protected areas in areas beyond national jurisdiction: The pioneering efforts under the OSPAR Convention' (2009) 5(1) Utrecht Law Review 5-20, pages 10-11.

153 For a discussion of these factors, see Gjerde and Rulska-Domino (n. 146); Kristina M. Gjerde et al., Regulatory and Governance Gaps in the International Regime for the Conservation and Sustainable Use of Marine Biodiversity in Areas beyond National Jurisdiction (IUCN, 2008). 
absence of systematic procedures for environmental impact assessments, as noted in the previous section. Moreover, the absence of a global process for the establishment of MPAs further complicates any attempt to designate a protected area. ${ }^{154}$ Most importantly, however, no one entity has jurisdiction in respect of the conservation and protection of the marine ecosystem and its living resources in areas beyond national jurisdiction. The fact that the high seas are res communis and human activities in marine spaces are regulated through a sectoral approach has resulted in no one entity being mandated to declare areas that are fully protected from various human activities, such as fishing, pollution, and seabed mining. Instead numerous organisations have jurisdiction over specific marine areas or individual activities, yet leaving parts of the high seas with no regional agreements in place. ${ }^{155}$ This situation makes it difficult to establish and manage integrated MPAs across sectors ${ }^{156}$ and to take cumulative impacts and additional effects from climate change and ocean acidification into account.

In order to address these issues, a number of states and non-governmental organisations have been lobbying for a new international agreement to regulate the protection of marine biodiversity in areas beyond national jurisdiction, including through the establishment of MPAs. ${ }^{157}$ While the LOsC already provides for the preservation and protection of the marine environment, a new agreement could regulate the designation of multi-purpose MPAs in areas beyond national jurisdiction to overcome both the jurisdictional gap and the fragmented, sectoral approach in the Losc. ${ }^{158}$ However, as discussed in Chapter 4.5, opinions over the desirability of a new agreement still diverge to some degree and, according to the current roadmap, it will likely be some years until a new agreement might be negotiated.

Instead of waiting until a new instrument might be adopted, the OSPAR Commission, established under the OSPAR Convention, ${ }^{159}$ has already acted.

154 Druel et al. (n. 110), page 16.

155 For an overview of the competencies, overlaps, and gaps of the various organisations, see Natalie C. Ban et al., 'Systematic Conservation Planning: A Better Recipe for Managing the High Seas for Biodiversity Conservation and Sustainable Use' (2014) 7 Conservation Letters 41-54; Gjerde et al. (n. 153); Druel et al. (n. 110), pages 13-14.

156 Jeff Ardron et al., 'The Sustainable Use and Conservation of Biodiversity in ABNJ: What Can Be Achieved Using Existing International Agreements?' (2014) 49 Marine Policy 98-108.

157 ввNJ Working Group, UN Doc A/69/780* (13 February 2015).

158 UN Doc A $/ 69 / 780^{*}$ (n. 157), paragraph 12.

159 Convention for the Protection of the Marine Environment of the North-East Atlantic (adopted 22 September 1992, entered into force 25 March 1998) 2354 UNTS 67. 
Unlike most regional seas agreements, the OSPAR Convention covers significant areas outside the limits of national jurisdiction. ${ }^{160}$ The OSPAR Ministerial Meeting in 2003 adopted a recommendation to establish a network of marine protected areas in the North-East Atlantic including in areas beyond national jurisdiction. ${ }^{161}$ Subsequently, seven protected areas have been established by OSPAR in the high seas, ${ }^{162}$ although their practical effect might be impeded because the OSPAR Commission can neither regulate all uses in these areas, nor rely on strong enforcement mechanisms. ${ }^{163}$

In light of the repeated calls for, and indeed a gradual progress towards, establishing protected areas in areas beyond national jurisdiction despite the overall jurisdictional gap, the role of the ISA is significant. Its jurisdiction covers prospecting, exploration, and exploitation of seabed minerals on the entire international seabed, protection of the marine environment from the effects of such activities, and marine scientific research in the Area. Although its mandate concentrates on seabed mining and does not allow for regulation of deep sea fishing or other destructive activities, the ISA can make a significant contribution towards establishing networks of marine protected areas ${ }^{164}$ not least because it has an extensive environmental mandate, law-making powers, an established institutional framework, and enforcement powers. ${ }^{165}$

\subsubsection{Mandate of the ISA to Declare Marine Protected Areas}

The LOSC does not mention marine protected areas specifically and the ISA has not yet included them in the Mining Code. However, the Losc indirectly provides for the protection of certain areas from seabed mining activities, which was developed further in the Mining Code as the following analysis demonstrates.

\footnotetext{
160 Ibid., article 1(a).

161 OSPAR Recommendation 2003/3 on a Network of Marine Protected Areas. The recommendations were updated in 2010, see OSPAR Recommendation 2010/2.

162 B.C. O'Leary et al., 'The First Network of Marine Protected Areas (MPAs) in the High Seas: The Process, the Challenges and Where Next' (2012) 36 Marine Policy 598-605; Petra Drankier, 'Marine Protected Areas in Areas beyond National Jurisdiction' (2012) 27(2) The International Journal of Marine and Coastal Law 291-350, pages 312-318; Molenaar and Oude Elferink (n. 152).

163 Nele Matz-Lück and Johannes Fuchs, 'The Impact of OSPAR on Protected Area Management beyond National Jurisdiction: Effective Regional Cooperation or a Network of Paper Parks?' (2014) 49 Marine Policy 155-166.

164 Stuart Kaye, 'Implementing high seas biodiversity conservation: global geopolitical considerations' (2004) 28(3) Marine Policy 221-226, page 225.

165 Chapters $3,5 \cdot 2$.
} 
In the context of assessing applications for exploration contracts, the ISA Council has, under Article 162(2)(x) LOSC, the power to disapprove areas for exploitation in cases where 'substantial evidence indicates the risk of serious harm to the marine environment.' The Legal and Technical Commission has the corresponding task to recommend such action. ${ }^{166}$ Moreover, the Exploration Regulations require the Commission to not recommend approval of a plan of work for exploration if it covers an area disapproved for exploitation under Article $162(2)(\mathrm{x}){ }^{167}$ Similarly, prospecting shall neither be undertaken in areas disapproved for exploitation, nor if there is substantial evidence indicating a risk of serious harm to the marine environment. ${ }^{168}$ Consequently, once an area has been disapproved for exploitation on environmental grounds, it is also closed for subsequent exploration and prospecting activities. Given that this measure can result in the prohibition of seabed mining activities in a specific area, it may be regarded as a spatial management tool. This power is consistent with the obligation set out in Article 194(5) LOSC, which requires states to 'protect and preserve rare or fragile ecosystems as well as the habitat of depleted, threatened or endangered species and other forms of marine life.'169

Nonetheless, the scope of this mandate is limited by the fact that closing an area for mineral exploitation work requires the presence of 'substantial evidence' for the risk of serious harm. Neither the Losc nor the Exploration Regulations define what is meant by substantial evidence. In any case, such evidence would likely be acquired through the compulsory EIAs and monitoring programme required during the exploration phase. ${ }^{170}$ However, the same standard of evidence applies to prospecting activities, which although regulated by the Exploration Regulations, is largely conducted freely in the form of marine scientific research. Requiring 'substantial evidence' in the prospecting context sets a high evidentiary threshold which appears impracticable given both the early stage of the activities and the high degree of uncertainty over deep sea ecosystem processes. In fact, setting a high evidentiary burden could be argued to defeat the purpose of the precautionary approach because the very nature of the approach implies the existence of uncertainty, arguably rendering it impossible to provide substantial evidence. This holds true especially for a preliminary activity such as prospecting. The notion of evidence

\footnotetext{
166 LOsC, article $165(2)(\mathrm{l})$.

167 Nodules Exploration Regulations, regulation 21(6); Sulphides and Crusts Exploration Regulations, regulation 23(6).

168 Exploration Regulations, regulation 2.

169 Losc, article 194(5).

170 Chapter 5.4.1.
} 
implies the need for prospectors to carry out some form of EIA to be able to determine whether serious harm might arise. ${ }^{171}$ However, neither do the Regulations require future prospectors to undertake such EIAs, nor would it always be feasible to acquire such data given the early stages of deep sea scientific research. As of July 2016 no areas have been disapproved either for prospecting, exploration, or exploitation, not least because the exploitation phase is yet to commence. However nine protected areas have been established as discussed in Chapter 6.3.1.

What remains unclear, however, is whether areas may only be disapproved for seabed mining upon receipt of an application for exploitation, or whether the ISA may use Article $162(2)(\mathrm{x})$ to proactively identify relevant areas and disapprove mining activities therein. However, reliance on Article 162(2)(x) is not necessary in order to proactively establish marine protected areas, as Article 145 grants broad powers to the ISA to take 'necessary measures' to ensure marine environmental protection. ${ }^{172}$ The Legal and Technical Commission has the specific obligation to make recommendations to the Council on 'the protection of the marine environment, taking into account the views of recognized experts in that field. ${ }^{173}$ There are no restrictions as to the focus or form of such recommendations. As such, the LTC is, in principle, able to recommend the establishment of marine protected areas. The Council, under Article 162 LOSC, has the competence to establish specific policies 'on any question or matter within the competence of the Authority' and can implement recommendations from the LTC with regard to spatial management. ${ }^{174}$ Indeed, it is on this basis that the ISA has established no-mining areas in the ClarionClipperton Zone. ${ }^{175}$

The Mining Code provides for a further way in which particular areas of seafloor may be protected from seabed mining. The Exploration Regulations require that LTC

shall develop and implement procedures for determining, on the basis of the best available scientific and technical information [...] whether

171 Harrison (n. 1), page 138.

172 Michael W. Lodge, 'Some Legal and Policy Considerations Relating to the Establishment of a Representative Network of Protected Areas in the Clarion-Clipperton Zone' (2011) 26(3) The International Journal of Marine and Coastal Law 463-480; Drankier (n. 162), pages 294-295.

173 Losc, article $165(2)(\mathrm{e})$.

174 See also Lodge (n. 172).

175 Chapter 6.3.1. 
proposed exploration activities in the Area would have serious harmful effects on vulnerable marine ecosystems and ensure that, if it is determined that certain proposed exploration activities would have serious harmful effects on vulnerable marine ecosystems, those activities are managed to prevent such effects or not authorized to proceed. ${ }^{176}$

The Exploration Regulations for sulphides and crusts specifically add ecosystems associated with hydrothermal vents, seamounts, and cold-water corals as examples for vulnerable marine ecosystems. ${ }^{177}$ This provision could ultimately allow for exploration work to be prohibited in areas of vulnerable ecosystems.

These tasks are not specifically provided for under the LOSC, although a justification for such measures may be implied from Articles 145, 194(5), and 197. Article 145 provides for the taking of 'necessary measures' specifically for the 'prevention of damage to the flora and fauna of the marine environment.' Similarly, Article 194(5) requires the protection and preservation of 'rare or fragile ecosystems as well as the habitat of depleted, threatened or endangered species and other forms of marine life.' Moreover, Article 197 requires states to take into account 'characteristic regional features' when elaborating international rules and standards for marine environmental protection.

These provisions were first included in the Sulphides Exploration Regulations, adopted in 2010. They mirror the language used in UN General Assembly Resolution 61/105, which calls upon regional fisheries management organisations to assess whether individual bottom fishing activities would have significant adverse impacts on vulnerable marine ecosystems. ${ }^{178}$ If found to have such impacts, bottom fishing must also be 'managed to prevent such impacts, or not authorized to proceed. ${ }^{\prime 179}$ Building on this Resolution, the FAO has recently commenced the 'Global Sustainability Fisheries Management and Biodiversity Conservation in Areas Beyond National Jurisdiction' programme. ${ }^{180}$ It comprises a programme specifically aimed at reducing the impact of deep sea fisheries on biodiversity in the deep oceans. Such

176 Nodules Exploration Regulations, regulation 31(4).

177 Sulphides and Crusts Exploration Regulations, regulation 33(4).

178 UNGA, Un Doc A/REs/61/105 (8 December 2006), paragraphs 83(a), (c).

179 Ibid.; see also UNGA, UN Doc A/REs/64/72 (19 March 2010), paragraphs 114-130.

180 The programme was approved by the Council of the Global Environment Facility (GEF) in November 2011. The FAO coordinates its implementation in close collaboration with inter alia the UN Environment Programme (UNeP) and the World Bank. See Common Oceans-Global Sustainability Fisheries Management and Biodiversity Conservation in Areas Beyond National Jurisdiction (FAO, 2014), page 1. 
coordination of conservation efforts will be necessary, not least because the aforementioned ecosystems occupy space on both the seafloor and in the water column. Given the sectoral fragmentation of ocean governance, it will be necessary for the ISA to coordinate its efforts with respect to seabed mining in the Area with other organisations that manage further activities that impact these ecosystems.

In sum, it is widely accepted that spatial tools, especially marine protected areas, must be part and parcel of efforts to protect the resilience of the marine environment and its biodiversity from ever increasing human pressure on the oceans. However, the sectoral approach taken in the Losc fragments ocean governance into various specific regimes, leaving a jurisdictional gap and a lack of competence to establish integrated, multi-purpose marine protected areas in areas beyond national jurisdiction. Discussions are underway for a potential new agreement addressing this and other management aspects for marine biodiversity in areas beyond national jurisdiction. Nonetheless, regardless of the outcome and in default of a new agreement, the ISA plays a central role in protecting marine biodiversity from human interference. The ISA has the competence to establish marine protected areas, albeit not expressly stated in the regulatory framework. Moreover, it has developed some of its environmental obligations to include special measures for the protection of vulnerable marine ecosystems. The question now is whether these are implemented in practice, which is discussed in Chapter 6.4.

\subsubsection{Best Environmental Practices}

A further obligation not specifically contained in the Losc, yet integrated into the Exploration Regulations is the requirement for the ISA and sponsoring states, ${ }^{181}$ as well as for prospectors ${ }^{182}$ and contractors ${ }^{183}$ to apply best environmental practices. These can be tools to ensure effective environmental protection and 'generally refer to widely-accepted norms or customs of environmental and risk management.'184

These requirements were first incorporated into the Sulphides Exploration Regulations in 2010 and subsequently in the Crusts Exploration Regulations

\footnotetext{
181 Nodules Exploration Regulations, regulation 31(2). Sulphides and Crusts Exploration Regulations, regulation 33(2).

182 Exploration Regulations, regulation 5(1).

183 Nodules Exploration Regulations, regulation 31(5); Sulphides and Crusts Exploration Regulations, regulation 33(5); Exploration Regulations, annex IV section 5(1).

184 ISA, Environmental Management Needs for Exploration and Exploitation of Deep Sea Minerals (ISA Technical Study No. 10) (ISA, 2012), page 33.
} 
and in the 2013 amendments of the Nodules Exploration Regulations. Thus, the contracts concluded pursuant to the original Nodules Exploration Regulations, adopted in 2000, do not contain such obligations. Nonetheless, the Seabed Disputes Chamber found that states who sponsored exploration activities under the early Regulations still have to apply best environmental practices, first, as a direct obligation under the Mining Code ${ }^{185}$ and, second, as part of their due diligence obligation to ensure the contractor complies with his obligations. ${ }^{186}$ Regarding the former, despite the obligation to apply best environmental practices only being included in the then latest Sulphides Exploration Regulations, the Chamber found that the first Nodules Exploration Regulations 'should be interpreted in light of the development of the law, as evidenced by the subsequent adoption of the Sulphides Regulations. ${ }^{.187}$ As a result, although the contractors who are exploring nodules pursuant to the original Nodules Exploration Regulations are not bound to apply best environmental practices, their sponsoring states are.

\subsubsection{Emergency Orders}

The LOSC mandates the ISA to adopt emergency measures to act promptly to prevent or contain environmental harm. ${ }^{188}$ The Exploration Regulations elaborate on the powers by adding procedural obligations. Before commencing exploration work, each contractor is required to submit a contingency plan 'to respond effectively to potentially harmful incidents. ${ }^{189}$ More specifically, contractors are obliged to promptly notify the ISA Secretary-General of 'any incident arising from activities which have caused, are causing or pose a threat of serious harm to the marine environment. ${ }^{\prime 190}$ In case such situation eventuates, emergency orders may be issued by the Council following the recommendation by the Legal and Technical Commission, and may include suspension or adjustment of operations. ${ }^{191}$ Moreover, pending any action by the Council, the ISA Secretary-General has the competence to take immediate measures of a temporary nature, for no longer than 90 days, 'as are practical and reasonable

\footnotetext{
185 SDC Advisory Opinion, paragraph 122.

186 Ibid., paragraph 136.

187 Ibid., paragraph 137 .

188 Losc, articles $162(2)(\mathrm{w}), 165(2)(\mathrm{k})$.

189 Exploration Regulations, annex 4, section 6.1.

190 Nodules Exploration Regulations, regulation 33(1); Sulphides and Crusts Exploration Regulations, regulation 35(1).

191 LOSC, articles 162(2)(w), 165(2)(k); Nodules Exploration Regulations, regulations 33(4)-(6); Sulphides and Crusts Exploration Regulations, regulations 35(4)-(6).
} 
in the circumstances to prevent, contain and minimize serious harm or the threat of serious harm to the marine environment.'192

In case the contractor does not comply with an emergency order the Council can take 'such practical measures as are necessary to prevent, contain and minimize any such serious harm or threat of serious harm to the marine environment.'193 Importantly, the contractor is required to reimburse the ISA for the expenses incurred in taking such measures. ${ }^{194}$ This can ensure a prompt response to emergencies while upholding the polluter-pays principle. ${ }^{195}$ However, as is discussed in Chapter 6.6, significant challenges remain with respect to implementing these provisions in practice.

\subsubsection{Enforcement and Liability}

As discussed in Chapter 3.6, the ISA has a far-reaching enforcement mandate pursuant to the LOSC to exercise such control 'as is necessary for the purpose of securing compliance' with the seabed mining regime. ${ }^{196}$ The Exploration Regulations reaffirm this position of the ISA and require contractors to submit a written undertaking accepting the control by the ISA over exploration and exploitation activities. ${ }^{197}$ The exploration contracts require contractors to submit annual reports about their activities. ${ }^{198}$ Moreover, they reiterate the ISA's power to inspect vessels and installations used by contractors to carry out their exploration work and to monitor the contractor's compliance as well as the effects of the contractor's activities on the marine environment. ${ }^{199}$ The contracts elaborate on the inspection mandate by setting out that logs, equipment, facilities, and 'other recorded data' and relevant documents are subject to inspections. ${ }^{200}$ However, as with emergency orders, the real challenge lies in implementing these obligations in practice, which is hampered by the ISA's current institutional structure and lack of resources. These challenges are examined in Chapter 8.2.2.

192 Nodules Exploration Regulations, regulation 33(3); Sulphides and Crusts Exploration Regulations, regulation 35(3).

193 Nodules Exploration Regulations, regulation 33(7); Sulphides and Crusts Exploration Regulations, regulation $35(7)$.

194 Exploration Regulations, annex 4, section 6.4.

195 Harrison (n. 1), page 140.

196 Losc, articles 153, 165(2)(c), (m), 165(3), annex III article 18.

197 Exploration Regulations, annex IV section 13.

198 Ibid., section 10.

199 Ibid., section 14.

$200 \quad$ Ibid., section 14. 
The Exploration Regulations also develop the rules regarding liability for environmental harm. As discussed in Chapter 3.6.2, sponsoring states are under the responsibility to ensure that contractors comply with their obligations under the exploration contracts. Non-compliance entails liability. The standard terms for exploration contracts expressly extend to contractors a liability for damage to the marine environment, except in cases of force majeure. ${ }^{201}$ Moreover, the Exploration Regulations state that contractors are responsible for 'any damage arising out of wrongful acts in the conduct of its operations, in particular damage to the marine environment, after the completion of the exploration phase. ${ }^{202}$ As such, contractors can be held liable for environmental harm, pursuant to their contractual obligations. However, as Bothe points out, this liability can only be enforced by the ISA owing to the contractual nature of the relationship. The ISA will have to consider the interests of third parties, such as other users of the marine resources, when developing its future exploitation regulations. ${ }^{203}$

Despite the fact that the Exploration Regulations develop the legal framework regarding enforcement as well as the potential liabilities of actors involved in activities in the Area, numerous questions remain. These include the potential liabilities of sub-contractors and the enforcement of the legal framework following the closure of a mine site. However, these questions are beyond the scope of this study and will have to be addressed in future research.

\subsubsection{Applying a Precautionary Approach}

The final and perhaps most important obligation the Mining Code expressly incorporates into the seabed mining regime is the need to apply the precautionary approach. Although neither the LOSC, nor the IA mention precaution, Chapter 4.4 demonstrated that the precautionary approach has been gradually integrated into the agreements by way of interpreting them in an evolutionary manner. In line with this evolution, the ISA has expressly integrated precaution into the Mining Code, eliminating any residual doubt over the applicability of the principle in the seabed mining context. The Exploration Regulations specifically state:

\footnotetext{
201 Ibid., sections 6.4, 17.

202 Nodules Exploration Regulations, regulation 30. Sulphides and Crusts Exploration Regulations, regulation 32 .

203 Michael Bothe, 'The Protection of the Marine Environment Against the Impacts of Seabed Mining: As Assessment of the New Mining Code of the International Seabed Authority' in Peter Ehlers, Elisabeth Mann Borgese, and Rüdiger Wolfrum (eds), Marine Issues (Kluwer, 2002) 221-231, page 230.
} 
In order to ensure effective protection for the marine environment from harmful effects which may arise from activities in the Area, the Authority and sponsoring States shall apply a precautionary approach, as reflected in principle 15 of the Rio Declaration, and best environmental practices. ${ }^{204}$

The Legal and Technical Commission must make recommendations to the Council with regards to implementing this obligation. ${ }^{205}$ However, as of July 2016, only one recommendation has been made specifically referring to this obligation to apply precaution, namely to adopt the Environmental Management Plan for the Clarion-Clipperton Zone. ${ }^{206}$

In addition to exploration work, a precautionary approach must also be applied during the prospecting phase. ${ }^{207}$ Moreover, through incorporating precaution into the exploration contracts, the ISA extends this obligation to contractors. The standard contract clauses state:

The Contractor shall take necessary measures to prevent, reduce and control pollution and other hazards to the marine environment arising from its activities in the Area as far as reasonably possible applying a precautionary approach and best environmental practices. ${ }^{208}$

Applying precaution, therefore, becomes a contractual obligation and the sponsoring state has the corresponding responsibility to ensure contractors comply. ${ }^{209}$

There may be some confusion as to which part of the sentence the words 'as far as reasonably possible' relate to. Does it limit the general, protective measures to what is reasonably possible, or does it qualify the obligation to apply precaution? It is suggested that the former is the correct interpretation, since the corresponding provision in the body of the Regulations, quoted above, includes a comma before mentioning precaution: '[...] each contractor shall take necessary measures to prevent, reduce and control pollution and other

204 Nodules Exploration Regulations, regulation 31(2); Sulphides and Crusts Exploration Regulations, regulation 33(2).

205 Nodules Exploration Regulations, regulation 31(3); Sulphides and Crusts Exploration Regulations, regulation 33(3).

206 ISA, ISBA /17/C/13 (13 July 2011), paragraph 28, Chapter 6.3.1.

207 Exploration Regulations, regulations 2(2), 5(1).

208 Exploration Regulations, annex IV section 5.1 (emphasis added).

209 SDC Advisory Opinion, paragraph 133. 
hazards to the marine environment arising from its activities in the Area as far as reasonably possible, applying a precautionary approach and best environmental practices. ${ }^{210}$

Importantly, the original Nodules Exploration Regulations, adopted in 2000, only required the ISA and sponsoring states to apply a precautionary approach but did not require contractors or prospectors to do so. ${ }^{211}$ This extension was first included in the Sulphides Exploration Regulations and was subsequently incorporated in the 2013 revision of the Nodules Exploration Regulations. This evidences a gradual strengthening and indeed widening of the obligation to apply the precautionary approach within the regulatory work of the ISA over the past two decades.

However, it also means that the 13 exploration contracts concluded under the original Nodules Exploration Regulations do not expressly include the obligation for contractors to apply precaution. Nevertheless, clearly aiming to close this gap for the contractors involved, the Seabed Disputes Chamber in its Advisory Opinion on the Responsibilities and Obligations of States Sponsoring Persons and Entities with Respect to Activities in the Area highlighted that under the general obligation of due diligence every sponsoring state is under an obligation 'to take measures within the framework of its own legal system in order to oblige sponsored entities to adopt [the precautionary] approach.'212

It should be noted that the direct reference to Principle 15 of the Rio Declaration in the Exploration Regulations introduces an element of discretion by requiring the application of precaution by states 'according to their capabilities.' It follows, as the Seabed Disputes Chamber noted, that the requirements under the precautionary approach may differ for developing and developed states. ${ }^{213}$ However, this does not diminish the obligation incumbent on the ISA, as an international organisation. Moreover, the Seabed Disputes Chamber attempted to reduce any discretion by noting that 'the reference to "capabilities" is only a broad and imprecise reference to the differences in developed and developing states. What counts in a specific situation is the level of scientific knowledge and technical capability available to a given state in the relevant scientific and technical fields. ${ }^{214}$ Additionally, as discussed in Chapter 3.6.2,

\footnotetext{
210 Nodules Exploration Regulations, regulation 31(5); Sulphides and Crusts Exploration Regulations, regulation 33(5).

211 ISA, ISBA/6/A/18 (13 July 2000), regulation 31(2).

212 SDC Advisory Opinion, paragraph 134.

213 SDC Advisory Opinion, paragraph 161.

214 Ibid., paragraph 162.
} 
the Chamber also allows for precaution as an element of due diligence to apply equally to all states not least to prevent 'sponsoring States "of convenience".'215

Consequently, applying the precautionary approach is an unequivocal requirement for the ISA, states, and contractors in the context of seabed mining. However, the challenge lies in implementing it. At the 2011 ISA workshop on Environmental Management Needs for Exploration and Exploitation of Deep Sea Minerals, the working group on legal issues identified a need for more guidance on how to operationalize the precautionary approach in the context of [deep seabed mining]. ${ }^{216}$ Such guidance is particularly pertinent in light of the widespread misunderstanding regarding the content of the precautionary principle. ${ }^{217} \mathrm{~A}$ poignant example is the discussion during the development of the Nodules Exploration Regulations. In 1999, the Netherlands submitted a proposal to incorporate the precautionary principle in the then draft regulations. ${ }^{218}$ In subsequent discussions, '[s] ome delegations however considered that, in view of the uncertainty associated with seabed exploration, it would be difficult, if not impossible, to identify and apply precautionary measures. ${ }^{219}$ Fortunately, this blatant misapprehension of when the precautionary principle must be applied was not shared by other delegations and the principle was eventually incorporated in the Nodules Exploration Regulations.

\subsubsection{Precautionary Thresholds in the ISA Context}

Having established the ISA's obligation to apply the precautionary approach, we need to examine where the threshold for precaution lies in the ISA context. As elaborated in Chapter 2.3, the precautionary approach comprises three elements, namely (a) a threat of environmental harm, (b) uncertainty, and (c) remedial action. In order to trigger the obligation to take remedial action, however, a certain threshold of risk, that is gravity times probability of harm, must be reached. The aim is to exclude precaution from being invoked for every minor or imaginary threat.

The present section relates this threshold test to the ISA context by analysing the formulations of precaution that are most relevant for the present study. In this context, Article 145 LOSC states:

\footnotetext{
215 Ibid., paragraphs 158-16o.

216 ISA Technical Study 10 (n. 184), page 33.

217 Chapters 2.1, 2.2.

218 ISA, ISBA/5/C/L.8 (25 August 1999).

219 ISA, ISBA/6/C/INF.1 (March 2000), paragraph 15.
} 
Necessary measures shall be taken in accordance with this Convention with respect to activities in the Area to ensure effective protection for the marine environment from harmful effects which may arise from such activities. ${ }^{220}$

The same formulation is reiterated in the Exploration Regulations which specifically spell out the requirements to apply a precautionary approach:

In order to ensure effective protection for the marine environment from harmful effects which may arise from activities in the Area, the Authority and sponsoring States shall apply a precautionary approach, as reflected in principle 15 of the Rio Declaration, and best environmental practices. ${ }^{221}$

Both these provision specify that the threat in question derives from potential, harmful effects from the activities in the Area. Moreover, the Exploration Regulations add the precautionary approach as 'the primary tool by which this protection from harmful effects is to be achieved. ${ }^{222}$ As for the thresholds involved, the provisions contain reference to both gravity and probability of harm, namely 'harmful effects which may arise.' However, the Mining Code adds a direct reference to the Rio Declaration which introduces an additional set of thresholds, the familiar 'threats of serious or irreversible damage.'

In order to protect the environment, the precautionary approach shall be widely applied by States according to their capabilities. Where there are threats of serious or irreversible damage, lack of full scientific certainty shall not be used as a reason for postponing cost-effective measures to prevent environmental degradation. ${ }^{223}$

In addition, the Seabed Disputes Chamber enunciated a surprisingly low threshold for states' obligation to apply the precautionary approach as an element of due diligence:

The due diligence obligation of the sponsoring States requires them to take all appropriate measures to prevent damage that might result from

\footnotetext{
220 LOSC, article 145.

221 Nodules Regulations, regulation 31(2); Sulphides and Crusts Regulations, regulation 33(2) (emphasis added).

222 ISA, ISBA/12/C/2 (Part II) (24 May 2006), paragraph 28.

223 Rio Declaration, principle 15 (emphasis added).
} 
the activities of contractors that they sponsor. This obligation applies in situations where scientific evidence concerning the scope and potential negative impact of the activity in question is insufficient but where there are plausible indications of potential risks. ${ }^{224}$

\section{The Probability Thresholds}

All these formulations provide for uncertainty. Their respective thresholds, which state the likelihood that harm occurs, (may, plausible indications, or simply threats) allow a wide scope of precautionary obligations.

Furthermore, for those activities which under the Exploration Regulations require a higher likelihood of harm, the probability threshold has been lowered in the more recent Exploration Regulations. For example, the original Nodules Exploration Regulations, adopted in 2000, provided for emergency orders in case of an 'incident resulting from or caused by a contractor's activities in the Area that has caused, or is likely to cause, serious harm to the marine environment.'225 In contrast the later Exploration Regulations require emergency orders for an incident 'that has caused, is causing or poses a threat of serious harm to the marine environment. ${ }^{226}$ These changes were based on the Legal and Technical Commission's considerations 'that the use of the term "likely to cause serious harm" as a trigger for action to be taken in pursuance of a precautionary approach implied a degree of certainty that was incompatible with the precautionary approach, which requires that there be only a threat of serious damage. ${ }^{227}$

\section{The Gravity Thresholds}

However, the formulations differ in regard to the gravity of the impact. The due diligence obligation of states already applies in circumstances of potential risks. The obligation of the ISA is captured in two different formulations. Harmful effects allows for broader precautionary protection than serious or irreversible damage, which raises the question, which one applies. Several observations may be made in this regard.

First, the wording in the Exploration Regulations is copied from Article 145 LOSC (and Article 17(2)(f) of Annex III) which predates the rise of precaution. Thus, it might be difficult to hold the wording of these provisions against the

\footnotetext{
224 SDC Advisory Opinion, paragraph 131 (emphasis added).

225 ISA, ISBA/6/A/18 (13 July 2000), regulation 32(1) (emphasis added).

226 Nodules Exploration Regulations, regulation 33(2); Sulphides and Crusts Exploration Regulations, regulation 35(2) (emphasis added).

227 ISBA/12/C/2 (n. 222), paragraph 29.
} 
thresholds that trigger the precautionary approach. However, in accordance with the Vienna Convention on the Law of Treaties, ${ }^{228}$ subsequent agreements and state practice are relevant. In this context, the IA, modifying Part XI at a time when precaution was being incorporated into virtually every new agreement, ${ }^{229}$ strengthened the ISA's focus on environmental protection. ${ }^{230}$ Moreover, the Exploration Regulations were being developed when the rhetoric of precaution had become omnipresent in international environmental law. Thus, the importance of the reiteration of the wording of Article 145 may be regarded as an acceptance of the threshold incorporated therein. In a $1998 \mathrm{draft}$ of the regulation the reiteration of Article 145 and the obligation to apply precautionary measures were linguistically separated. ${ }^{231}$ Yet, the Council rephrased the provision and, in its 1999 draft, specifically linked the two by requiring precautionary measures 'pursuant to article $145 .{ }^{232}$ Similarly, the final version explicitly requires a precautionary approach 'in order to' ensure effective protection for the marine environment.

Second, any mining activity is likely to cause some damage. Thus, at first glance, the requirement of merely harmful effects may be of limited use in establishing a specific obligation. However, omitting a specific threshold for the gravity of harm is common practice and, despite an obvious intention of the drafters to ensure a high level of environmental protection, a minimum threshold may nevertheless be inferred to render the precautionary approach workable. ${ }^{233}$ Moreover, it is questionable whether the risks associated with activities at the exploration and exploitation stage would fall beneath a minimum threshold of significant. Given the sensitivity of many deep sea environments and the high levels of uncertainty, a precautionary obligation with a wide reach appears to have been a prudent choice by the drafters of the Regulations.

228 Vienna Convention on the Law of Treaties, (adopted 23 May 1969, entered into force on 27 January 1980) 1155 UNTS 331, article 31(3).

229 David Freestone and Ellen Hey, 'Origins and Development of the Precautionary Principle' in David Freestone and Ellen Hey (eds) The Precautionary Principle and International Law: the Challenge of Implementation (Kluwer Law International, 1996) 3-15, page 3.

$230 \quad$ IA, preamble paragraph 3; Chapter 4.2.

231 Draft regulation 28 stated: 'Each contractor shall ensure the effective protection of the marine environment from serious harm which may arise from its activities in the Area and shall take precautionary measures to anticipate, prevent or minimize any adverse impacts on the marine environment in the Area as far as reasonably possible using best available technology.' ISA, ISBA/4/C/4/Rev.1 (29 April 1998) (emphasis added).

232 Ibid.

233 Arie Trouwborst, Precautionary Rights And Duties of States (Martinus Nijhoff Publishers, 2006), pages 47-48; Chapter 2.3.1. 
Third, further light can be shed on the matter by analysing the activities in the Area for which the Rio Declaration threshold of serious or irreversible damage is explicitly required. Interestingly, irreversibility is neither referred to in the LOSC, nor in the Mining Code. This may be welcomed since it can be problematic to determine whether an effect is irreversible or merely longlasting. ${ }^{234}$ This is especially difficult in relation to impacts in the deep sea for which long-term studies are mostly lacking. The requirement of serious harm was added to the wording of Article 145 in the above mentioned 1998 draft regulations ${ }^{235}$ but was ultimately rejected and a direct reference to the Rio Declaration was included instead. In the final version of the Regulations, serious harm is used primarily in relation to emergency measures, ${ }^{236}$ disapproving prospecting or exploitation at specific sites, ${ }^{237}$ and applying additional protective measures or even prohibiting exploration work where it would have serious harmful effects on vulnerable marine ecosystems. ${ }^{238}$ Similarly, in the LOSC, serious harm is only required for provisional measures, ${ }^{239}$ emergency orders, ${ }^{240}$ and disapproval of sites. ${ }^{241}$ These examples show that serious harm is used as the threshold that may lead to mining activities being halted or prohibited. Consequently, a lower threshold to trigger general precautionary obligations would be consistent with an implicit hierarchy of precautionary measures in the Regulations.

Fourth, it should be noted that Regulation 1 of the Exploration Regulations defines 'serious harm to the marine environment' as:

any effect from activities in the Area on the marine environment which represents a significant adverse change in the marine environment determined according to the rules, regulations and procedures adopted by the Authority on the basis of internationally recognized standards and practices. ${ }^{242}$

\footnotetext{
234 Ibid., pages 6o-62.

235 ISBA/4/C/4/Rev.1 (n. 231), regulation 28.

236 Nodules Exploration Regulations, regulation 33; Sulphides and Crusts Exploration Regulations, regulation 35 .

237 Nodules Exploration Regulations, regulations 2, 21(6)(c); Sulphides and Crusts Exploration Regulations, regulations 2, 23(6)(c).

238 Nodules Exploration Regulations, regulation 31(4); Sulphides and Crusts Exploration Regulations, regulation 33(4).

239 LOSC, article 290(1).

240 LOSC, articles 162(2)(w); 165(2)(k).

241 LOsC, articles $162(2)(\mathrm{x}) ; 165(2)(\mathrm{l})$.

242 Exploration Regulations, regulation 1(3)(f).
} 
In short, serious is expressly defined as significant, even though the former may appear to convey a higher threshold. Consequently, any reference in the Mining Code to serious harm, or indeed the Rio Declaration, may be interpreted as encompassing a lower threshold than what is assumed at first sight. In other words, this definition reduces the difference in gravity thresholds under the LOSC and the Mining Code (harmful effects) on the one hand and the Rio Declaration (serious or irreversible damage) on the other hand. In fact, an analysis of the draft Exploration Regulations for sulphides and crusts prepared by the ISA Secretariat in 2006 specifically notes that it may be argued that consistency is achieved by the definition of the term "serious harm to the marine environment" in regulation 1 as a proxy for the "harmful effects" referred to in article 145 of the Convention. ${ }^{243}$ In any case, the EIA Recommendations expressly list those activities 'in the exploration area with potential to cause serious harm to the environment.'244 Not surprisingly, any drilling, rock sampling, or testing of mining equipment falls within this category. ${ }^{245}$ Consequently, these exploration activities are doubtlessly subject to the precautionary principle.

Fifth, besides these precautionary obligations for specific and very serious situations, there are good reasons to assume that precaution is to be applied broadly by the ISA. First, the Rio Declaration itself requires precaution to be 'widely applied.' Second, Article 145 LOSC imposes a general obligation to prevent harm to the marine environment and is not restricted to particularly vulnerable ecosystems or emergency situations. Third, within the Regulations, the obligation to apply precaution is included in the part dealing with the general protection and preservation of the marine environment. Thus, there is no reason to assume it only applies to particular situations, especially since emergency measures are covered by a separate regulation. ${ }^{246}$ Fourth, and perhaps most importantly, the Seabed Disputes Chamber has not only endorsed the precautionary approach but also broadened its application significantly, by identifying precaution as an integral element of the general due diligence obligation of sponsoring states. Thus, precaution becomes applicable even to activities outside the ISA Regulations 'where there are plausible indications of potential risks.'247

\footnotetext{
243 ISBA/12/C/2 (n. 222), paragraph 28.

244 EIA Recommendations (n. 57), paragraph 9.

245 Ibid., paragraph 19.

246 Nodules Exploration Regulations, regulation 33; Sulphides and Crusts Exploration Regulations, regulation 35 .

247 SDC Advisory Opinion, paragraph 131.
} 
In sum, the ISA is not only under an obligation to apply the precautionary principle but the thresholds for triggering precaution allow a wide scope of precautionary obligations. The probability threshold for harm occurring is low and has indeed been lowered further for specific activities under the Mining Code over the last 15 years. The gravity element for especially far-reaching measures is set at serious harm, which in turn is defined as significant adverse change. Moreover, general precautionary obligations seem to be required for harmful effects which may arise from exploration and exploitation work. ${ }^{248}$ In other words, the legal framework aims to provide for a high standard of environmental protection from seabed mining activities.

\section{The Definition of Harmful Effects and Significant Adverse Change}

The remaining question is how to define harmful effects and significant adverse change in the seabed mining context. The Exploration Regulations are largely silent on this crucial question and merely refer to 'internationally recognized standards and practices' in relation to the definition of significant adverse change. ${ }^{249}$

The draft regulations, prepared by the Preparatory Commission, did provide some detail, defining serious harm to the marine environment as:

any effect from activities in the Area on the living or non-living components of the marine environment and associated ecosystems beyond that which is negligible or which has been assessed and judged to be acceptable by the Authority pursuant to these regulations and the relevant rules and regulations adopted by the Authority and which represent:

(a) significant adverse changes in the living and non-living components of the marine and atmospheric environment;

(b) significant adverse changes in the ecosystem diversity, productivity and stability of the biological communities within the environment; or

(c) loss of scientific or economic values which is unreasonable in relation to the benefit derived from the activity in question. ${ }^{250}$

248 Nodules Exploration Regulations, regulation 31(2); Sulphides and Crusts Exploration Regulations, regulation 33(2).

249 Exploration Regulations, regulation 1(3)(f).

250 Preparatory Commission for the ISA and ITLOS, LOS/PCN/SCN.3/WP.6/Add.5 (8 February 1990), article 2(2). 
Guidance can also be drawn from the fisheries context. The Food and Agricultural Organisation defines significant adverse impacts in relation to deep sea fisheries in relation to compromise to an ecosystem's integrity: ${ }^{251}$

When determining the scale and significance of an impact, the following six factors should be considered:

i. the intensity or severity of the impact at the specific site being affected;

ii. the spatial extent of the impact relative to the availability of the habitat type affected;

iii. the sensitivity/vulnerability of the ecosystem to the impact;

iv. the ability of an ecosystem to recover from harm, and the rate of such recovery;

v. the extent to which ecosystem functions may be altered by the impact; and

vi. the timing and duration of the impact relative to the period in which a species needs the habitat during one or more of its life history stages. ${ }^{252}$

These examples demonstrate that any definition rests on two elements. First, it requires scientific advice regarding the activity's effect on biodiversity and ecosystem integrity as well as the spatial and temporal scale of the impact. This presupposes adequate data to establish environmental baselines and understand ecosystem structures, at least to some extent. Second, it requires an agreed, value-based environmental conservation objective to determine what is unreasonable or unacceptable change. Indeed, participants at a 2014 workshop by the Deep Ocean Stewardship Initiative 'recognized the extreme complexity of the issues and the enormous data gaps associated with assessing significant impact,' concluding:

Huge unknowns make the determination of significant impacts extremely difficult. Such unknowns include the questions related to species rarity and possible extinction; the ecological and social importance of extinction of a single deep sea species; numerical thresholds for significant impact; and ecosystem function [... . ${ }^{253}$

251 FAO, International Guidelines for the Management of Deep-Sea Fisheries in the High Seas (2009), paragraph 17.

252 Ibid., paragraph 18.

253 Deep Ocean Stewardship Initiative, Meeting Summary: Defining 'Significance' in Environmental Impact Assessment for Deep-Sea Mining (Scripps Institution of Oceanography, 26-28 March 2014) <http://dosi-project.org/dosi-outputs>. 
These considerations, including the scientific and the social dimension, must be addressed by the ISA, in accordance with its mandate to control seabed mining in the Area on behalf of humankind, to promote and conduct marine scientific research in the Area, and to protect the marine environment from harmful effects of seabed mining. ${ }^{254}$

\section{$5.5 \quad$ Conclusion}

The environmental mandate of the ISA is not static. On the contrary, as the present chapter demonstrates, the ISA continuously develops the regulatory framework for seabed mining, primarily through the Mining Code, which is binding on all ISA members regardless of individual consent.

In this context, the first conclusion to be drawn from this Part II of this study is the inherently evolutionary design of Part XI, which allows the ISA to adopt and review environmental regulations in line with new scientific understandings, current developments in international law, and the changing values society places on seabed minerals, biodiversity, and ecosystems and their functions. This evolutionary design is perhaps most visible when examining the gradual integration of the precautionary approach into the ISA regime. Through both customary international law as well as being implicitly required by the LOsC, the ISA is under an obligation to apply precaution to seabed mining activities. This obligation has been codified and further specified in the Exploration Regulations, which can thus be regarded as a preliminary step in implementing the principle.

In addition to the Exploration Regulations playing a role in the implementation of the ISA's environmental mandate, by virtue of their binding nature, they are also a source of legal obligations. In fact, the Seabed Disputes Chamber has relied on the Exploration Regulations to find that sponsoring states are under a direct obligation to apply the precautionary approach. ${ }^{255}$ As the Chamber observed:

The provisions of the aforementioned Regulations transform this nonbinding statement of the precautionary approach in the Rio Declaration into a binding obligation. The implementation of the precautionary

254 LOSC, articles 136, 137, 140, 143, 145, 153(1).

255 SDC Advisory Opinion, paragraphs 121-122, 125, 131. 
approach as defined in these Regulations is one of the obligations of sponsoring States. ${ }^{256}$

The Exploration Regulations, in turn, contribute to the development of international law. Thus, what is included in the Regulations can also affect how the LOSC is interpreted. This is again confirmed by the Seabed Disputes Chamber finding that precaution is also an element of the due diligence obligation of sponsoring states. In finding this connection, the Chamber relied, inter alia, on the fact that the ISA had included the obligation to apply precaution as a contractual obligation under the standard contract clauses annexed to the Exploration Regulations. ${ }^{257}$

The second conclusion from this chapter is that the ISA is under an obligation to apply extensive environmental requirements with the aim of ensuring the effective protection of the marine environment. This complements its explicit stewardship mandate to organise, carry out, and control seabed mining activities in the Area on behalf of humankind as a whole. ${ }^{258}$

The ISA's environmental mandate relates to the conduct of marine scientific research, assessing and monitoring the effects of seabed mining on the environment, and declaring areas protected from mining. However, as demonstrated in Section 5.4.1, the Mining Code fails to identify the objective of EIAS or to provide an indication of what to do if an EIA finds that an activity is likely to cause significant harm. Moreover, the ISA has, so far, failed to include strategic environmental assessments into the Mining Code. The IsA has allocated the responsibilities with respect to EIAs and the gathering of environmental baseline data to the contractors. Yet, the Mining Code does not incorporate a corresponding obligation of the ISA to provide strategic environmental assessments, which would incorporate both a macro-scale assessment of the need (or lack thereof) for seabed mining and a regional scale environmental assessment.

Directly linked to this omission is another important aspect missing from the Exploration Regulations, namely the development of the ISA's mandate to promote, encourage, and conduct marine scientific research concerning the Area. ${ }^{259}$ If the Mining Code was to allocate the responsibility to gather environmental data not only to contractors but also reiterate the ISA's responsibility in this regard, the ISA could target research efforts to fill the current gaps in the data and knowledge about the deep ocean environment. This would help

256 SDC Advisory Opinion, paragraph 127.

257 Ibid., paragraph 133.

258 Losc, article 153(1).

259 LosC, article 143. 
to better facilitate strategic environmental assessments and EIAs and it would be a strategic response to the challenge of identifying ways to minimise the environmental costs of seabed mining, in accordance with the IsA's mandate.

As this chapter demonstrates, the ISA has also developed its competencies regarding emergency measures and enforcement powers. Moreover, it has expressly integrated into the Mining Code the need to deploy best environmental practices and a precautionary approach in ensuring effective protection of the marine environment. The thresholds of both the probability and gravity of harm to trigger the precautionary principle are relatively low, providing for the potential to comprehensively protect the environment from a broad range of seabed mining activities. However, one important omission is a definition of the gravity thresholds of harmful effects and significant adverse change. This renders uncertain the point at which the ISA is required to take protective measures. This is also closely related to the conclusion drawn in Chapter 2: because the precautionary principle does not provide a blueprint for specific protective measures, the ISA must determine an agreed conservation objective and design its regulatory framework to achieve this objective.

In conclusion, the ISA is equipped with an extensive environmental mandate, law-making powers, enforcement competencies, and a stewardship mandate to act on behalf of humankind. Thus, 'the ISA is ideally placed to play a leadership role in the implementation of the goals and commitments relevant to the protection of biodiversity that have been endorsed by its member States in other fora. 260

This study could conclude here by stating that the precautionary principle is implemented in the ISA regime, as evidenced by the fact that it has been progressively incorporated into the ISA's regulatory framework. However, this would not only be premature but also misleading and indeed contribute to the widespread misperception as to what implementing the precautionary principle entails. Consequently, Part III examines the implementation of the precautionary principle by the ISA in practice.

260 Lodge (n. 172), page 470. 